Supporting Information

\title{
Electron Transfer Kinetics at Graphene Quantum Dot Assembly Electrodes
}

Marija R. Zoric,,$^{1,2}$ Varun Singh, ${ }^{1,2}$ Sean Warren, ${ }^{3}$ Samuel Plunkett, ${ }^{4,5}$ Renat $R$. Khatmullin, ${ }^{6}$ Brian P. Chaplin ${ }^{4}$ and Ksenija D. Glusac ${ }^{1,2, *}$

${ }^{1}$ Department of Chemistry, University of Illinois at Chicago, 845 W Taylor Street, Chicago, Illinois, 60607

${ }^{2}$ Chemical Sciences and Engineering Division, Argonne National Laboratory, 9700 Cass Ave, Lemont, Illinois, 60439

${ }^{3}$ Department of Chemical and Bimolecular Engineering, Georgia Institute of Technology, 311 Ferst Drive NW, Atlanta, Georgia, 30332

${ }^{4}$ Department of Chemical Engineering, University of Illinois at Chicago, 945 W Taylor Street, Chicago, Illinois, 60607

${ }^{5}$ Materials Science Division, Argonne National Laboratory, 9700 Cass Ave, Lemont, Illinois, 60439

${ }^{6}$ Department of Natural Sciences, Middle Georgia State University, 100 University Pkwy, Macon, Georgia, 31206

*glusac@uic.edu 


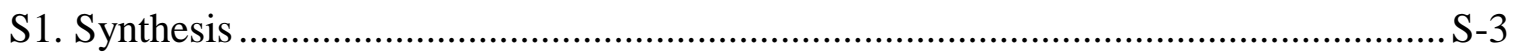

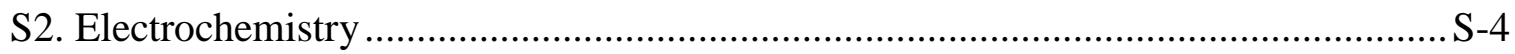

S3. Electrochemical deposition of QDs: CVs and UV-Vis .....................................

S4. Characterization of electrochemically deposited QDs ..........................................

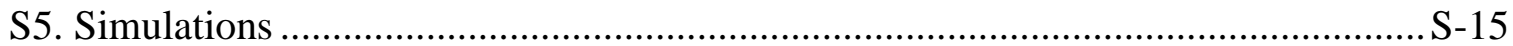

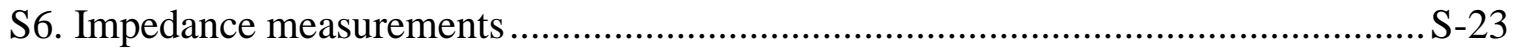

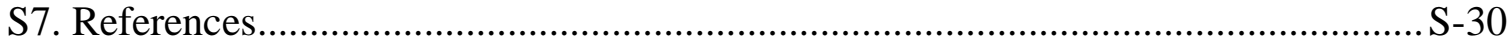




\section{S1. Synthesis}

HPB was purchased from commercial sources and used without further purification. Chemically synthesized HBC (c-HBC) was synthesized according to already published procedure, ${ }^{1-2}$ while pre-CQD and chemically synthesized CQD (c-CQD) were prepared as described in Scheme S1. Compounds 1 and 2 were synthesized according to previously published procedures. ${ }^{1-3}$
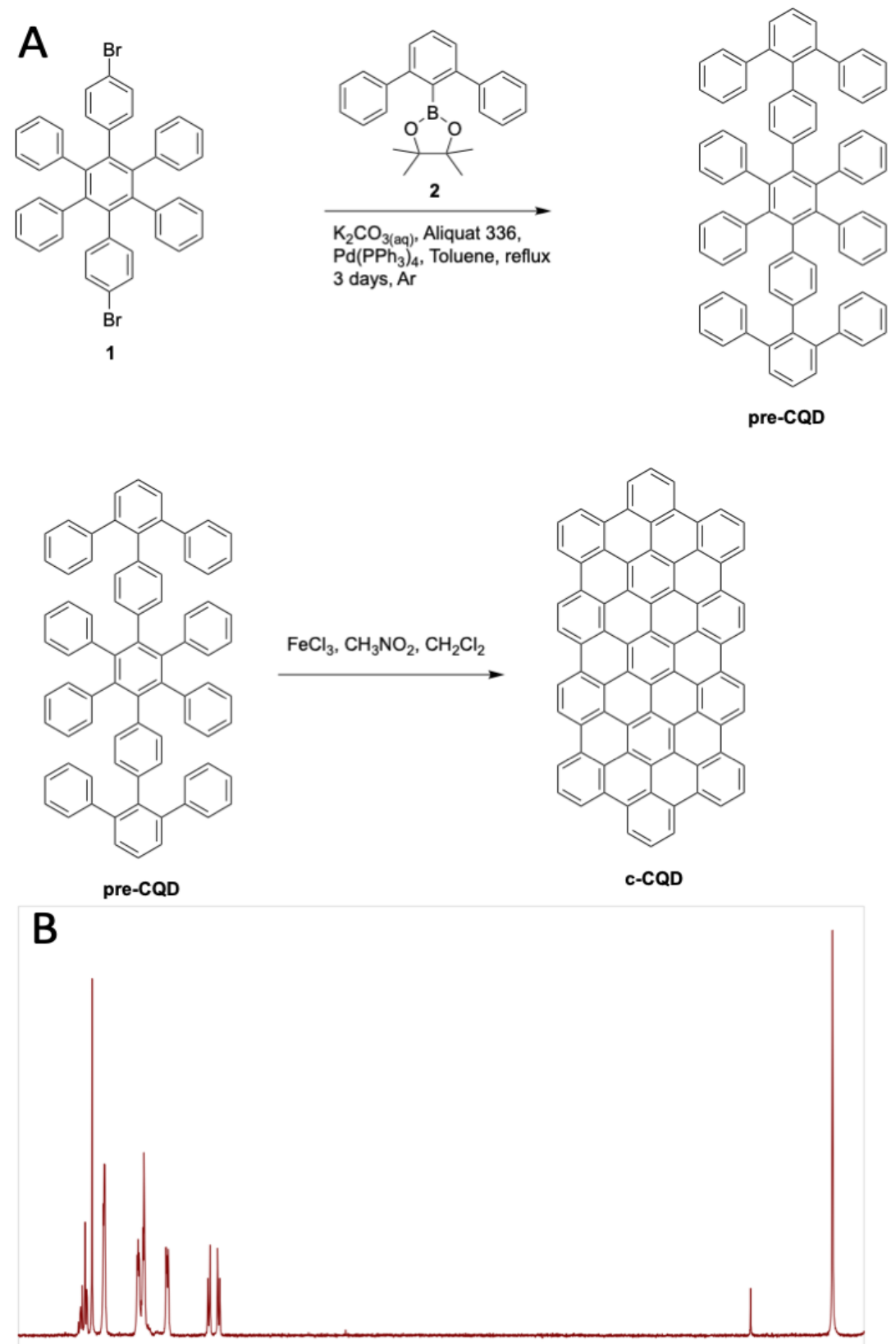

$\begin{array}{lllllllllllll}7.5 & 7.0 & 6.5 & 6.0 & 5.5 & 5.0 & 4.5 & 4.0 & 3.5 & 3.0 & 2.5 & 2.0 & 1.5\end{array}$ 
Figure S1. A) Synthetic route for preparation of pre-CQD and c-CQD; B) ${ }^{1} \mathrm{H}$ NMR spectrum of pre-CQD in $\mathrm{CD}_{3} \mathrm{Cl}$.

pre-CQD: A mixture of compounds $2(112 \mathrm{mg}, 0.315 \mathrm{mmol}), 1$ (100 mg, $0.150 \mathrm{mmol}), \mathrm{K}_{2} \mathrm{CO}_{3}$ $\left(2 \mathrm{M} / \mathrm{H}_{2} \mathrm{O}, 1.12 \mathrm{~g}, 8.1 \mathrm{mmol}\right)$ and Aliquat $336(1.2 \mathrm{mg}, 0.003 \mathrm{mmol})$ in toluene $(10 \mathrm{ml})$ was degassed three times via freeze-pump-thaw cycles. $\mathrm{Pd}\left(\mathrm{PPh}_{3}\right)_{4}(21 \mathrm{mg}, 0.018 \mathrm{mmol})$ was quickly added and the reaction mixture was degassed again via freeze-pump-thaw cycles. The reaction mixture was refluxed under argon for 3 days, then cooled to room temperature, quenched with water and extracted using dichloromethane (DCM). The organic fractions were collected, dried over $\mathrm{MgSO}_{4}$ and solvent was removed under vacuum. Silica gel column chromatography of the reaction mixture with hexane/DCM (2:1) yielded $110 \mathrm{mg}$ of product (75\% yield).

${ }^{1} \mathrm{H}$ NMR (400 MHz, $\left.\mathrm{CDCl}_{3}\right): \delta$ 6.28, d, 4 H; 6.37, d, 4 H; 6.68, m, 8 H; 6.80-6.95, m, 20 H; 7.137.20, m, $12 \mathrm{H} ; 7.28-7.38, \mathrm{~m} 6 \mathrm{H}$.

${ }^{13} \mathrm{C}$ NMR (125 MHz, $\left.\mathrm{CDCl}_{3}\right): \delta 125.14,125.99,126.42,126.97,127.43,129.89,130.02,130.39$, 130.69, 131.66, 135.39, 137.71, 138.29, 139.39, 140.32, 140.79, 141.70, 142.11.

MALDI $m / z 990.32$ (found) (990.42 calculated).

c-CQD: pre-CQD (50 mg, $0.050 \mathrm{mmol})$ in dry DCM $(50 \mathrm{ml})$ was purged with argon for 15 minutes. $\mathrm{FeCl}_{3}(344 \mathrm{mg}, 2.12 \mathrm{mmol})$ in dry nitromethane $(2 \mathrm{ml})$ was added dropwise under argon. The reaction mixture was kept under argon and stirred at room temperature for $16 \mathrm{~h}$. The reaction was quenched with methanol $(10 \mathrm{ml})$ and solvent was removed under vacuum. The black-colored solid was suspended in methanol, filtered and dried under vacuum to yield $34 \mathrm{mg}$ product (70\% yield). MALDI $m / z 962.3$ (found) (962.2 calculated).

\section{S2. Electrochemistry}

All electrochemical measurements were performed in a three-electrode cell setup. Reference electrode was non-aqueous 0.1 M Ag/AgNO 3 electrode (MF-2062, Bioanalytical systems), Pt wire was used as the counter electrode (MW-4130 or MW-1033, Bioanalytical systems), and glassy carbon (GC, MF-2012, Bioanalytical systems), Pt (MF-2013, Bioanalytical systems) or fluorine doped tin oxide (FTO, MSE Supplies) as working electrodes. All measurements were performed in $0.1 \mathrm{M}$ tetrabutylammonium hexafluorophosphate $\left(\mathrm{TBAPF}_{6}\right)$ solution in dichloromethane 
(DCM) as electrolyte. All potentials are referenced versus $0.1 \mathrm{M} \mathrm{Ag} / \mathrm{AgNO}_{3}\left(\mathrm{Ag} / \mathrm{Ag}^{+}\right)$electrode unless otherwise specified.

Electrochemical cyclodehydrogenation. Bulk electrolysis was performed in a two-compartment cell where one compartment contained the counter electrode, while the other housed working and reference electrodes. Vigorous stirring was applied during electrolysis. Concentration of starting materials (HPB or pre-CQD) for electrochemical cyclodehydrogenation reaction was $1 \mathrm{mM}$. The cyclodehydrogenation experiments were performed in Ar-filled glove box using anhydrous solvents. Electrolysis was accomplished at $1.65 \mathrm{~V}$ vs $\mathrm{Ag}_{/ \mathrm{Ag}^{+}}$until $20 \mathrm{mC}$ of charge passed through, followed by de-doping at $-1 \mathrm{~V}$. Films for variable scan rate experiments and experiments with ferrocene were prepared on Pt working electrode. Once the film was deposited, electrode was tested for hydrogen evolution reaction (HER) by running a $\mathrm{CV}$ scan in the cathodic region in acidic solution (0.1 M TBAPF 6 in DCM with $10 \mathrm{mM} \mathrm{HBF}_{4}$ ). HER is very prominent on Pt electrode at $\sim-0.2 \mathrm{~V}$ and absent on carbon-based electrodes at the same potential region. When HER current was not observed anymore, we concluded that surface of the Pt is covered by our films. Those film thicknesses were then used for further measurements.

Cyclic voltammetry. Variable scan rate experiments were performed in $\mathrm{TBAPF}_{6} / \mathrm{DCM}$ electrolyte using the previously described 3-electrode cell. Potential was scanned from $-0.5 \mathrm{~V} \rightarrow 1.6 \mathrm{~V} \rightarrow-$ $0.5 \mathrm{~V}$ varying scan rates from $10 \mathrm{mV} / \mathrm{s}$ to $4 \mathrm{~V} / \mathrm{s}$. Stability of the films was always tested by running 20 consecutive scans at $1 \mathrm{~V} / \mathrm{s}$ and comparing the as obtained CVs. The concentration of ferrocene was $3 \mathrm{mM}$.

Galvanostatic cyclic charge discharge (CCD) measurements. These experiments were performed using quantum dot (QD) films whose mass was calculated as follows: charge used for their deposition was reduced for the mass used for dedoping and film mass was calculated from charge difference. Current densities were varied from $2 \mathrm{~A} / \mathrm{g}$ to $50 \mathrm{~A} / \mathrm{g}$. Every film was tested using $\mathrm{CV}$ before $\mathrm{CCD}$ and after to confirm that there was not any degradation of the film during charging. 
In situ spectroelectrochemistry. Fluorine doped tin oxide (FTO) electrode were used for those experiments since they are transparent above $300 \mathrm{~nm}$. UV-Vis spectra were collected while simultaneously applying oxidative potential $(2.5 \mathrm{~V})$.

In situ spectroelectrochemical measurements on electrodeposited HBC and CQD films on FTO were recorded on the same experimental setup. UV-Vis was recorder in at different potentials from $-1.0 \mathrm{~V}$ to $1.7 \mathrm{~V}$ on every $100 \mathrm{mV}$. Controlled potential electrolysis was applied until stable current was observed (typically after $60 \mathrm{~s}$ ) and that UV-Vis was recorded. The film was than exposed to $1.0 \mathrm{~V}$ to make sure starting conditions are the same. CVs were recorder after each electrolysis to monitor film stability under the experimental conditions.

\section{S3. Electrochemical deposition of QDs: cyclic voltammograms and UV-Vis spectra}

Film growth can be easily visualized with CVs (Figures 1B and S2) where an increase in current of two broad peaks is observed upon cycling. Similarly, in situ UV-Vis spectroscopy is utilized to show peak growth (Figures 1C and S2). HBC (Figure S2) exhibit peak with a maximum $\sim 360 \mathrm{~nm}$, which was assigned to $\pi-\pi^{*}$ transition. ${ }^{4} \mathrm{CQD}$ (Figure 1B) exhibits absorption maximum at higher wavelengths $(\sim 440 \mathrm{~nm})$ due to larger conjugation of the system.
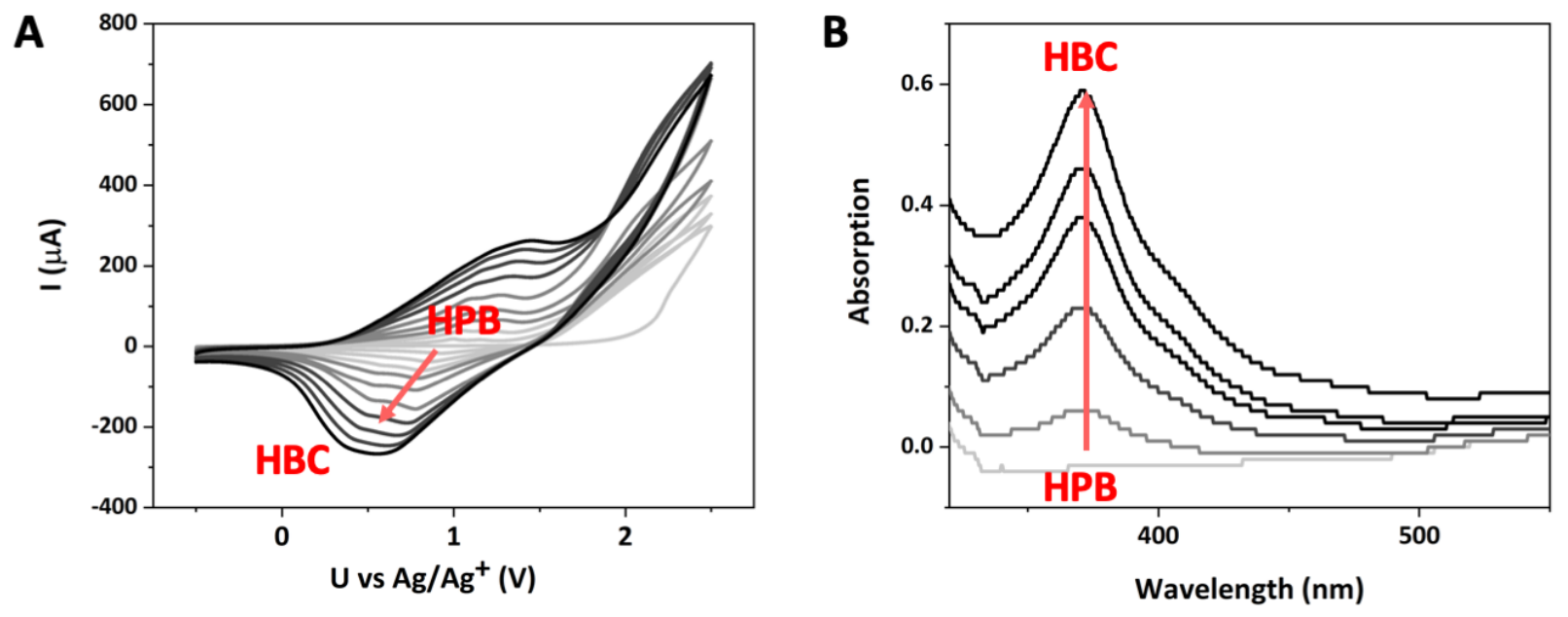

Figure S2. Growth of graphene quantum dot films on the electrode surface: A) Cyclic voltammograms and B) UV-Vis absorption spectra showing increase in peaks of HBC with every consecutive scan (FTO working electrode). 
The absorption spectra of c-HBC and e-HBC are slightly different (Figure S3). The discrepancy is likely due to different degrees of $\pi$-stacking between HBC units in two samples: c-HBC was measured as a suspension in solution, while e-HBC was measured in the solid state.
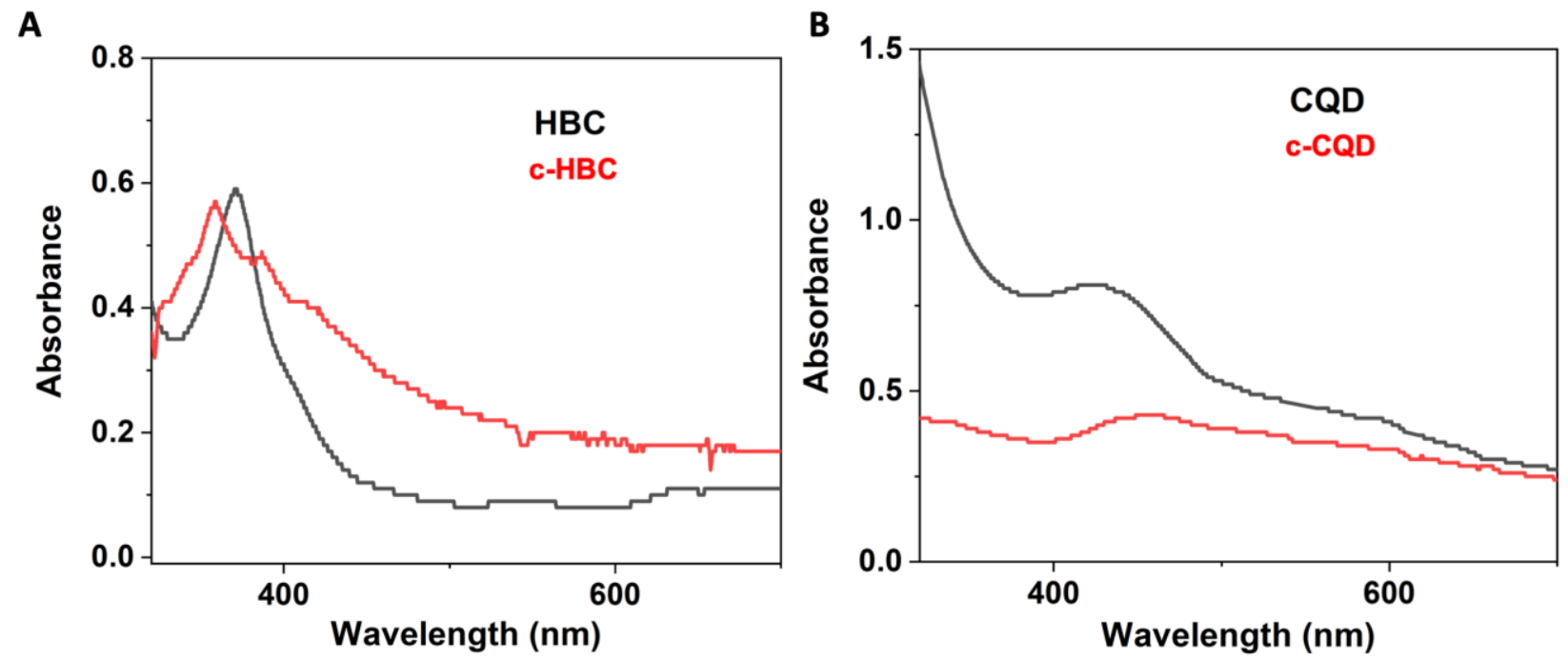

Figure S3. UV-Vis absorption spectra of electrochemically (black) and chemically synthesized graphene quantum dots: A) HBC and B) CQD. Spectra for electrochemically deposited HBC and CQD were recorded on the FTO substrate. Chemically synthesized c-HBC was recorded in toluene solution and c-CQD was mixed with poly(methyl methacrylate) in 1:1 mass ratio and dissolved in chloroform.

\section{S4. Characterization of electrochemically deposited QDs}

Electrodeposited films were scraped off of the electrode surface (glassy carbon) and MALDI mass spectra were collected. HBC showed peak at $\mathrm{m} / \mathrm{z} 522.1$ (predicted 522.1) indicating the presence of e-HBC. In addition, dimer formation is indicated by a peak at 1038. CQD exhibited peaks at $\mathrm{m} / \mathrm{z} 962.1$ (predicted 962.2) indicating the formation of e-CQD and a peak at 982.3 indicating that some incomplete oxidation products were present. No dimers were observed in MALDI of CQD. It is still possible that some higher mass products were formed, but that they fly poorly in MALDI. 

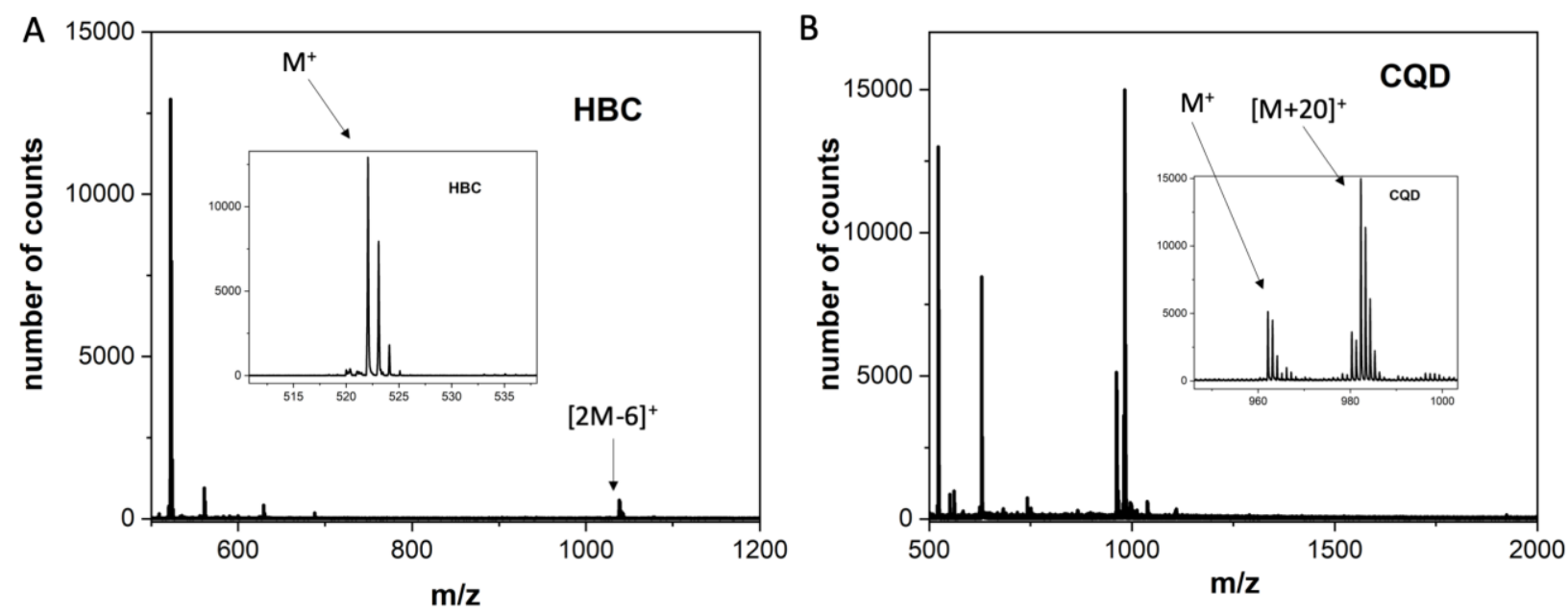

Figure S4. MALDI mass spectra of A) HBC and B) CQD. Insets show zoomed regions where molecular peaks are observed.

Raman spectroscopy is a powerful technique for characterization of graphitic materials due to distinct $\mathrm{D}$ and $\mathrm{G}$ band displayed in their spectra. ${ }^{5}$ The most prominent peak at $1599 \mathrm{~cm}^{-1}$ in CQD $\left(1601 \mathrm{~cm}^{-1}\right.$ in $\left.\mathrm{HBC}\right)$ is the so-called graphitic or G-band and its appearance is associated with inplane vibrations of $\mathrm{sp}^{2}$ carbon atoms (Figures S4A and S5A). Peaks at $\sim 1300 \mathrm{~cm}^{-1}(1336,1261$, and $1241 \mathrm{~cm}^{-1}$ for CQD and 1300 and $1254 \mathrm{~cm}^{-1}$ for $\mathrm{HBC}$ ) are associated with the disorder-induced D-band, which is related to various defects in graphene - in this case edge carbon atoms are considered to be "defects". In CQD spectra, G' (or 2D) band at $\sim 2700 \mathrm{~cm}^{-1}$ is also present. The same compounds were also chemically synthesized and characterized the same way. As shown in Figures S4A and S5A, they exhibit the same peaks as electrochemically prepared films. Precursors' peaks are absent from Raman spectra of QDs.

IR spectra were recorded for the films electrochemically deposited onto glassy carbon electrode. The films were scraped of the electrode surface, followed by $\mathrm{KBr}$ pill preparation (Figure S5B and S6B). The IR spectrum of HBC shows the presence of 767, 739, and $696 \mathrm{~cm}^{-1}$ out-of-plane deformation vibrational bands characteristic for 1,2,3-trisubstituted benzenes. In addition, the peak at $1571 \mathrm{~cm}^{-1}$ was observed corresponding to the C-C aromatic stretching vibration. The IR spectrum of CQD exhibits out-of-plane deformation vibrations corresponding to 1,2,3trisubstituded benzenes at 743,772, and $800 \mathrm{~cm}^{-1}$ and to 1,2,3,4-tetrasubstituted benzenes at 840 $\mathrm{cm}^{-1}$. Additional bands from C-C aromatic stretching vibrations were present from $1450-1710 \mathrm{~cm}^{-}$ 
${ }^{1}$. In both HBC and CQD IR spectra, bands of various intensities were present in the $900-1300 \mathrm{~cm}^{-}$ ${ }^{1}$ region corresponding aromatic in plane bending vibrations.
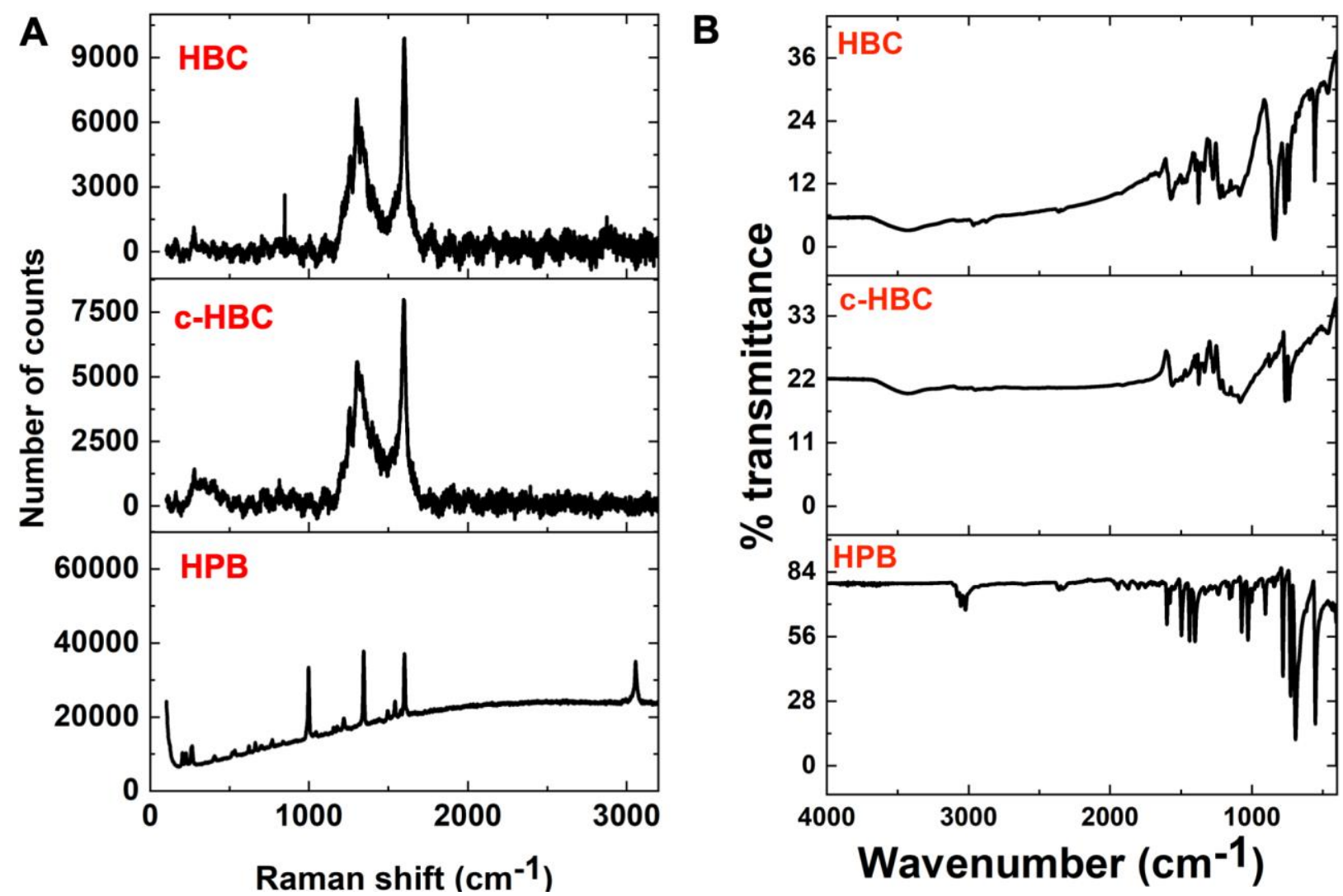

Figure S5. A) Raman spectra of HPB, c-HBC, and HBC. B) IR spectra of HPB, electrochemically synthesized HBC, and chemically synthesized c-HBC. 

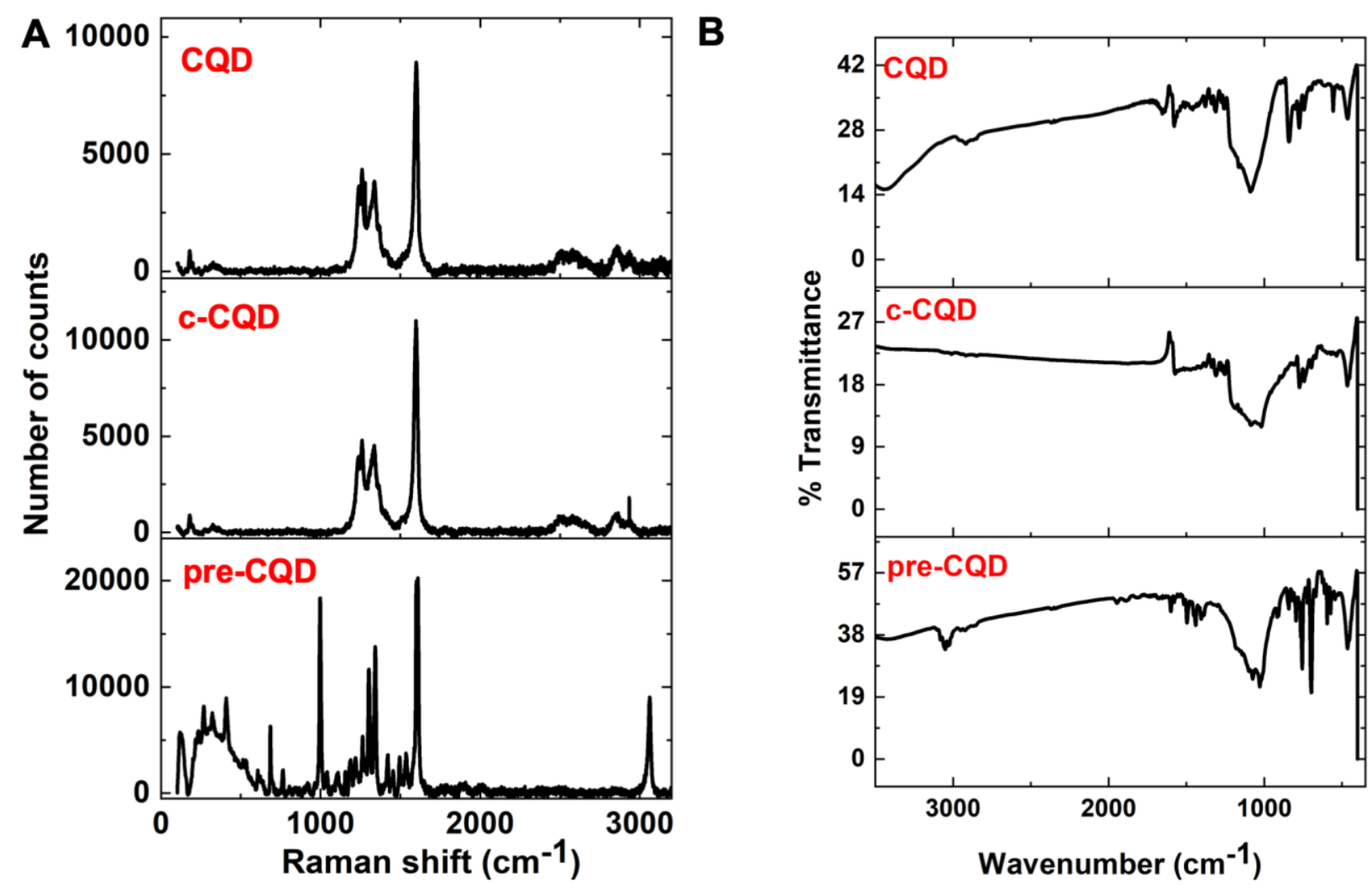

Figure S6. A) Raman spectra of pre-CQD, c-CQD and electrochemically synthesized CQD. B) IR of CQD, c-CQD, and pre-CQD.

Grazing-incidence wide-angle x-ray scattering (GIWAXS) was employed to study stacking patterns in HBC and CQD. HBC has a peak at $\mathrm{q} \sim 1.5$ and smaller peaks at 1.1 and $1 \AA^{-1}$ which correspond to distances of $0.4,0.57$, and $0.64 \mathrm{~nm}$ (Figure S7). This result is in a good agreement with TEM data showing $\pi-\pi$ stacking. Additionally, GIWAXS show very prominent peak at 0.55 $\AA^{-1}$ which corresponds to a distance of $1.14 \mathrm{~nm}$. This length corresponds to the diameter of HBC molecule and indicates ordered packing in the electrodeposited films in the direction of molecular plane. CQD also displays small intensity peaks at 1.5 and $1 \AA^{-1}$ which match 0.4 and $0.6 \mathrm{~nm}$ distance related to the $\pi-\pi$ stacking (Figure S8). Furthermore, strong peak at $0.29 \AA^{-1}$ with shoulder at $0.5 \AA^{-1}$ could be observed. Those bands can be related to $2.17 \mathrm{~nm}$ and $1.26 \mathrm{~nm}$ which is almost the exact length and width of CQD. This result indicates ordered structure along the both dimensions in the molecular plane. 2D GIWAXS plot (Figure S9) show that there is no preferred directionality in film growth. Both $\mathrm{HBC}$ and CQD grow in all directions relative to the FTO surface. 


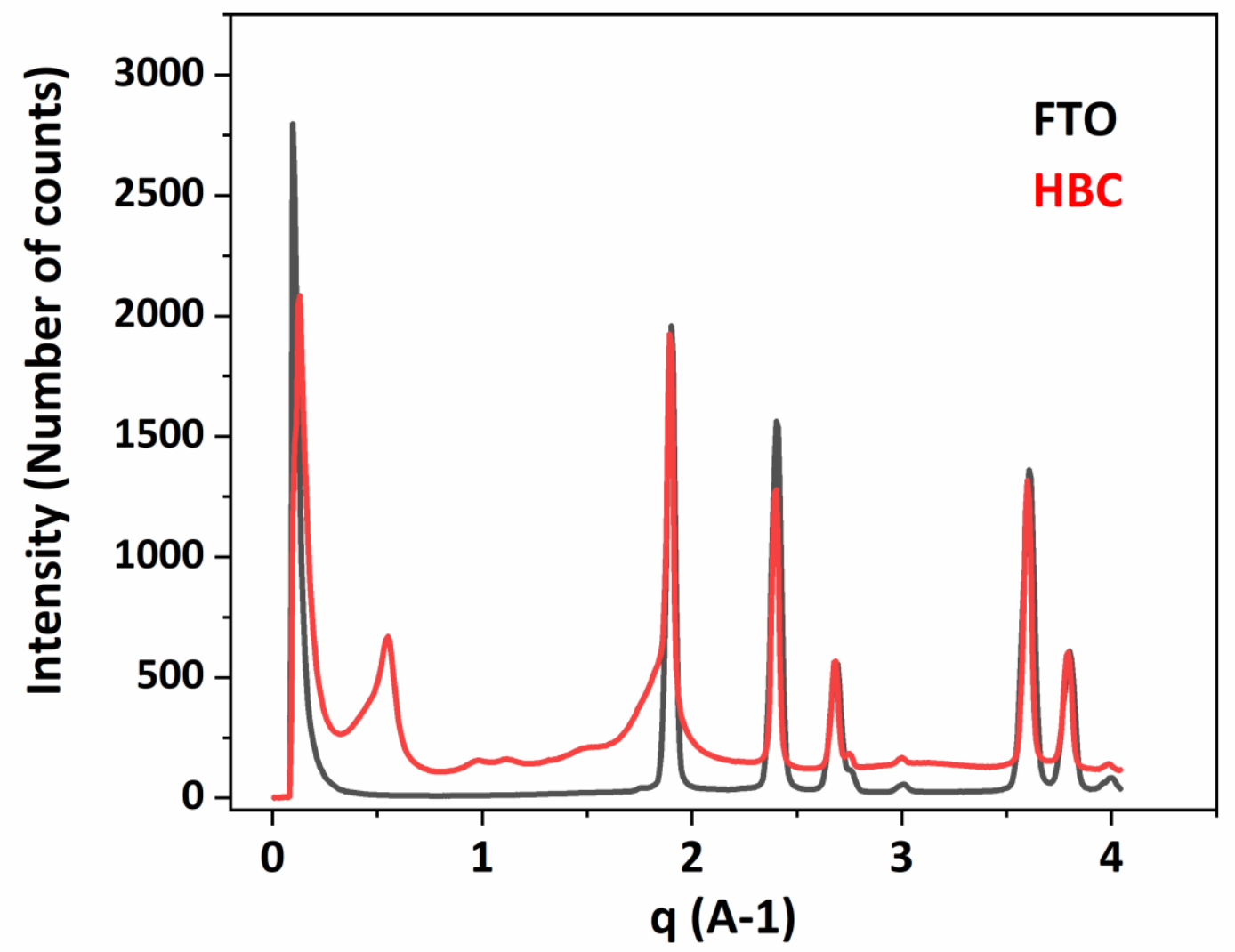

Figure S7. Grazing-incidence wide-angle x-ray scattering (GIWAXS) spectra of FTO and HBC deposited on FTO. 


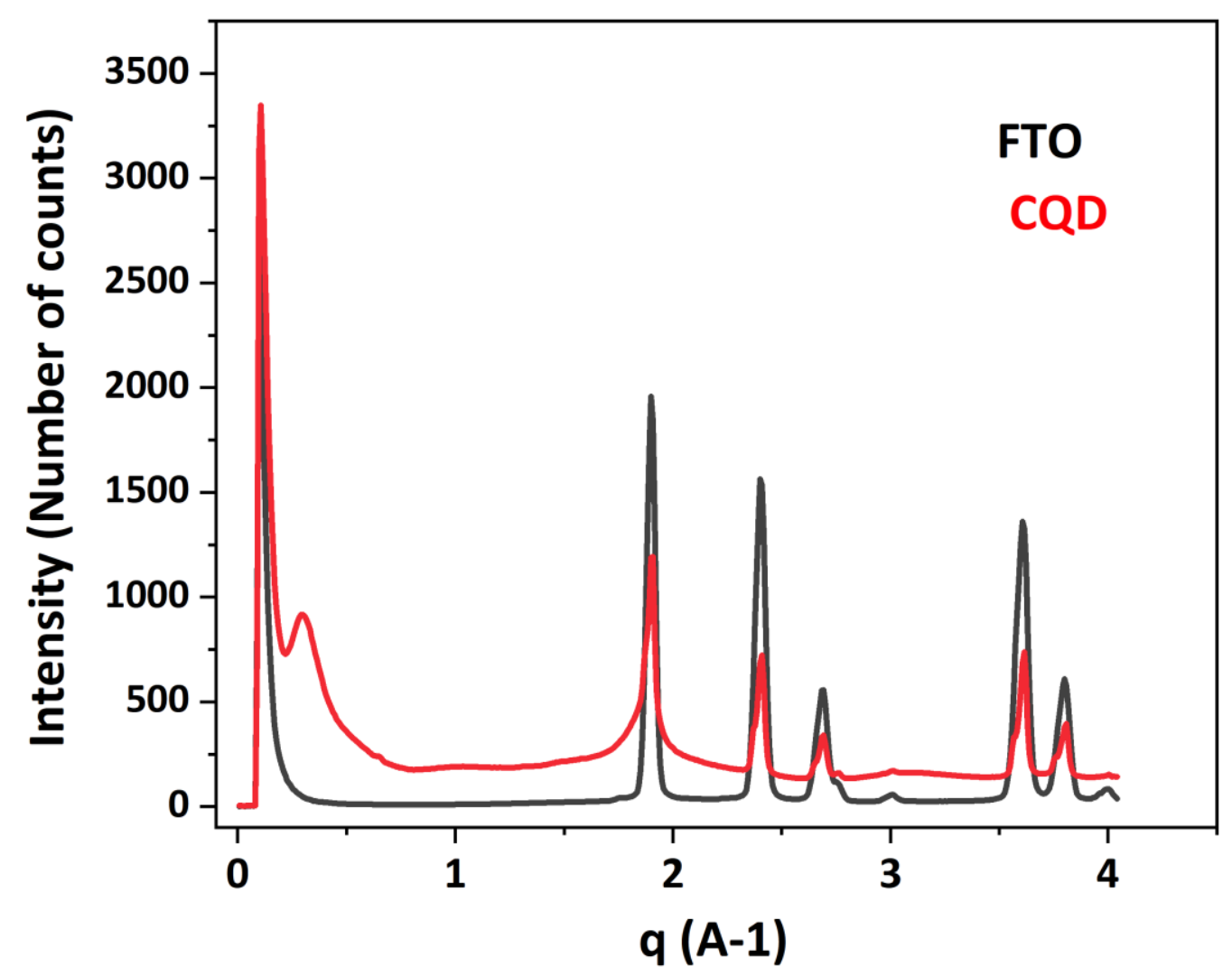

Figure S8. Grazing-incidence wide-angle x-ray scattering (GIWAXS) spectra of FTO and CQD deposited on FTO.
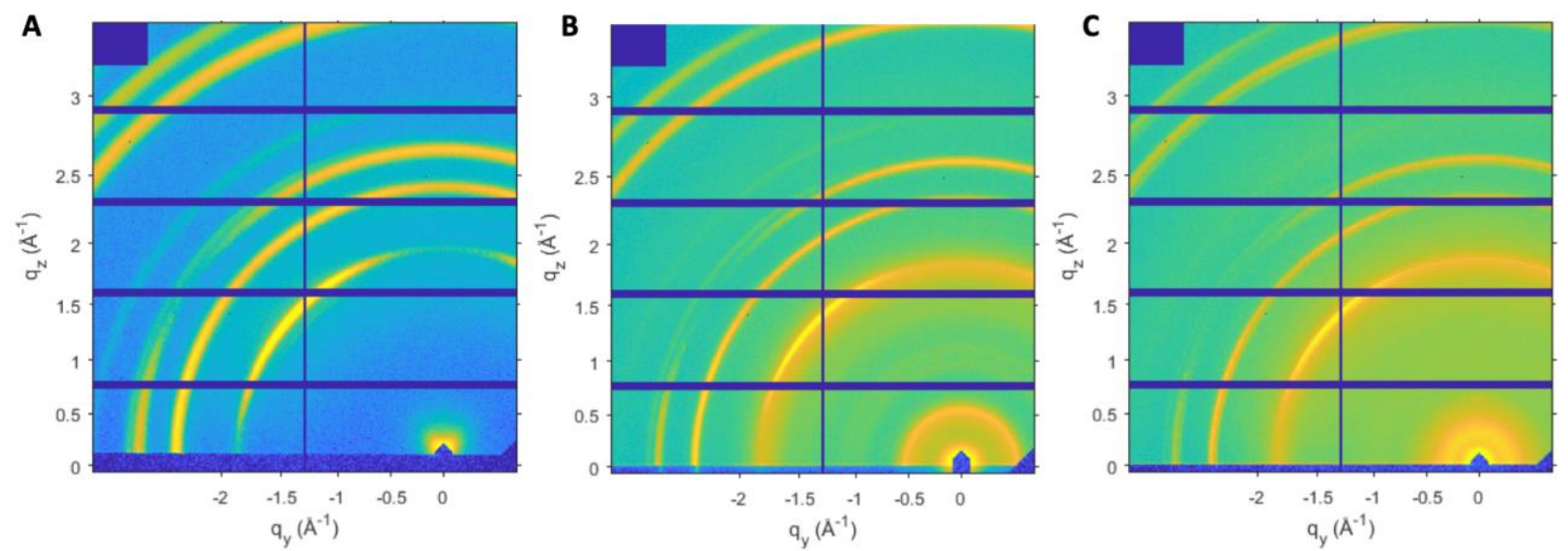

Figure S9. 2D plots of GIWAXS spectra of A) FTO, B) HBC deposited on FTO, and C) CQD deposited on FTO. 
Specific capacities of both HBC and CQD are relatively high for carbon-based electrodes. CQD shows a decay in capacity at higher current densities. This is an expected phenomenon since at higher current densities the rate of diffusion of the anions from the solution cannot compete with the charge buildup at the electrode surface. HBC shows a decrease in the capacity at low current densities as observed before. ${ }^{4}$ This is possibly due to the instability of the film in electrolyte on longer timescales required for $\mathrm{CCD}$ measurements on low current densities.

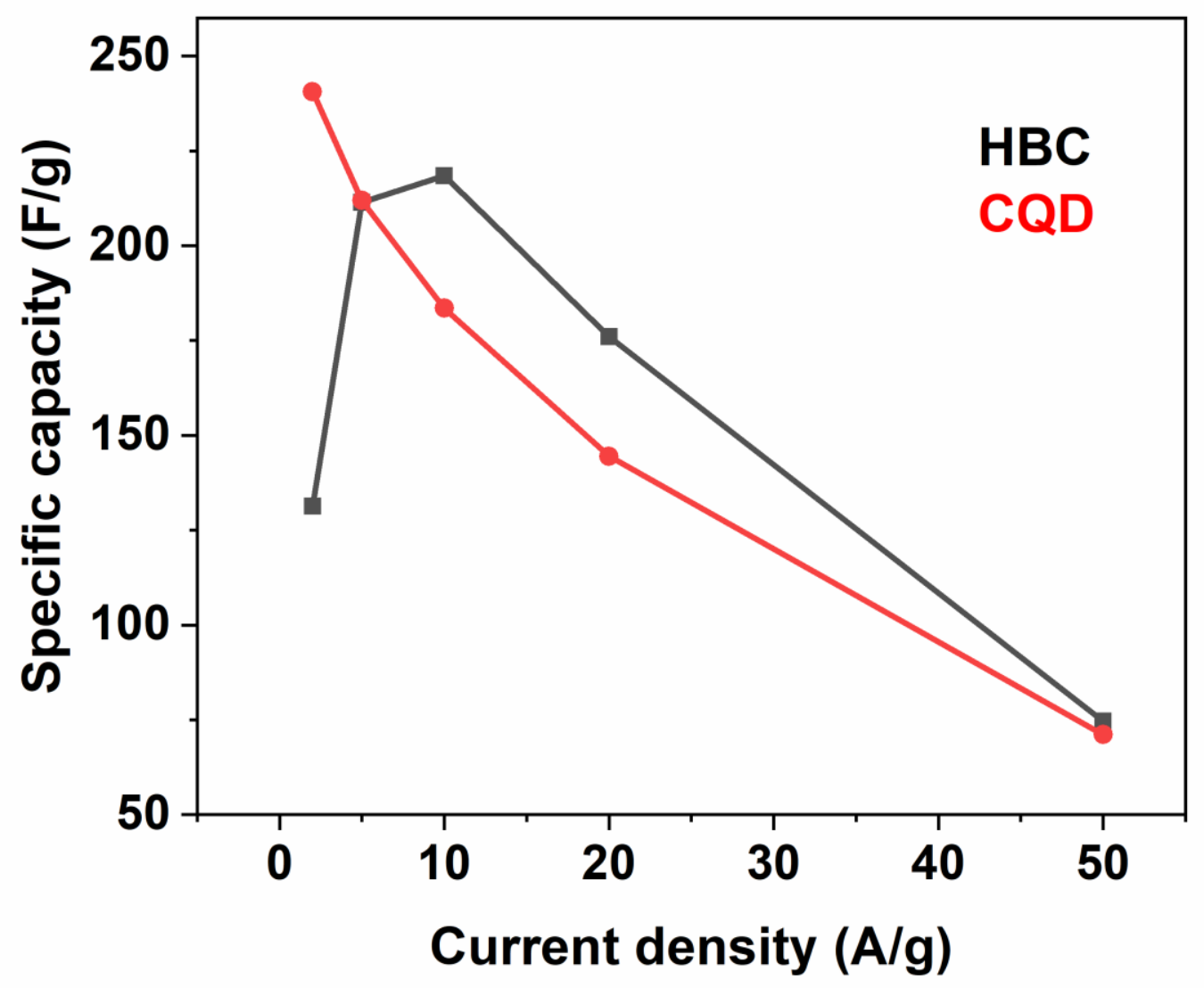

Figure S10. The specific capacitance as a function of current density for HBC (black) and CQD. Data were obtained from the galvanostatic cyclic charge-discharge experiments.

Spectroelectrochemical measurements on electrochemically synthesized HBC and CQD films were conducted to evaluate experimental DOS profiles. Figures S12A and S12C present UV-Vis spectra obtained at different applied potential for $\mathrm{HBC}$ and CQD respectfully. Absorption band at $360 \mathrm{~nm}$ for HBC film grows in intensity upon increasing oxidative potential. Similarly, absorption 
band at $358 \mathrm{~nm}$ in CQD film grows at more positive potential. When those absorbance values are plotted versus applied potential, the graphs qualitatively resemble DOS profiles for electrochemically deposited films (Figure S12B for HBC and S12D for CQD).
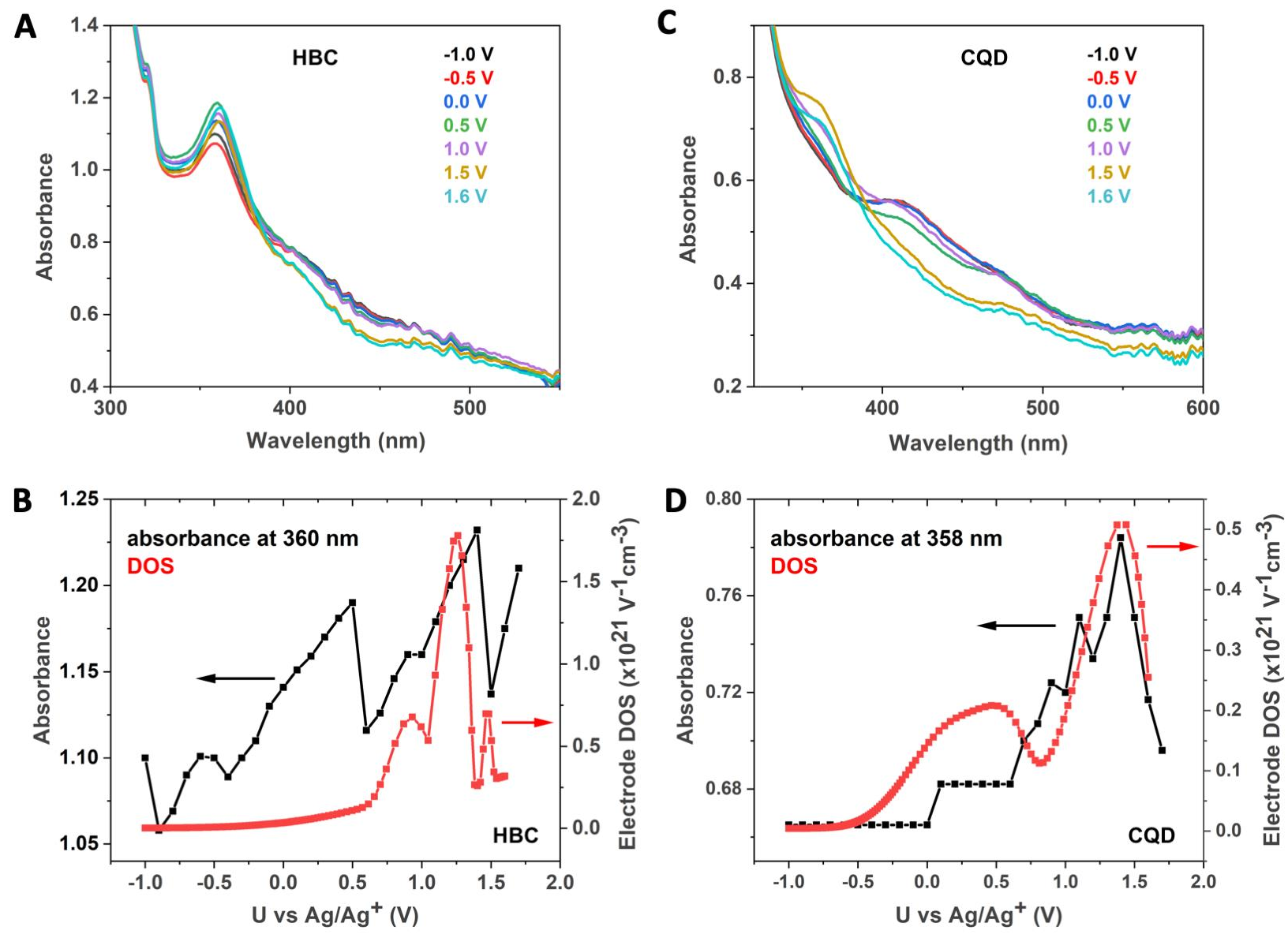

Figure S11. A) UV-Vis absorption spectra of HBC film on FTO under applied potential. B) Absorbance of $\mathrm{HBC}$ at $360 \mathrm{~nm}$ as a function of applied voltage (black) compared with DOS profile (red). C) UV-Vis absorption spectra of CQD film on FTO under applied potential. D) Absorbance of CQD at $358 \mathrm{~nm}$ as a function of applied voltage (black) compared with DOS profile (red). 


\section{S5. Simulations}

Capacitive Current: The voltammograms were modeled using the modification of a model developed by Bisquert and coworkers. ${ }^{6}$ The model uses series resistance, $\mathrm{R}_{\mathrm{s}}$, in addition to the capacitance (C) to describe film properties. In such a circuit, total voltage (V) is the sum of capacitive voltage $\left(\mathrm{V}_{\mathrm{C}}\right)$ and resistive voltage:

$V=V_{C}+V_{R}$

The current I is equal to the capacitive current $\left(\mathrm{I}_{\mathrm{C}}\right)$ and to the resistive current:

$I=I_{C}=I_{R}$

Combining equations 1 and 2, we can write:

$V=V_{C}+I_{C} R_{S}$

The intensity of current that passes through cell, could be expressed as:

$I_{C}=\frac{d q}{d t}=\frac{d q}{d V_{C}} \frac{d V_{C}}{d t}=C \frac{d V_{C}}{d t}$

where $\mathrm{q}$ is the charge and $\mathrm{t}$ is time. The chemical capacitance $\mathrm{C}$ is directly proportional to the occupancy of the electronic states in the material, which provides the link between DOS profiles and voltammetry experiment: ${ }^{7-8}$

$C=e^{2} \cdot d \cdot A \cdot D O S$

Here, e is the charge of an electron, $d$ and A are the thickness and the area of the film. DOS distribution in our model was obtained using a linear combination of four Gaussian building functions: 
$D O S=A_{O}+\sum_{i=1}^{4} A_{i} \cdot \exp \left(-\frac{\left(E_{o i}-E\right)^{2}}{\sigma_{i}^{2}}\right)$

Equations 3, 4 and 5 are combined into the following differential equation:

$\frac{d V_{C}}{d t}=\frac{1}{R_{S} \cdot C}\left(V-V_{C}\right)$

Here, $\mathrm{V}$ is expressed in terms of time using the initial voltage $\left(\mathrm{V}_{\mathrm{i}}\right)$, switching voltage $\left(\mathrm{V}_{\mathrm{f}}\right)$ and scan rate (s), as follows:

$V=V_{i}+s \cdot t$

$V=V_{f}-s \cdot t$

Equation 8 was used for the anodic scan and equation 9 was used for the cathodic scan. Differential equation (7) was solved and data were fit to the experimental values using Matlab. Gaussian function parameters (peak $E_{0 i}$, width $\sigma_{I}$, and amplitude $A_{i}$ ) and $R_{S}$ values were used to fit the experimental data. Table S1 lists the input and fitting parameters for the model.

Thickness of the film (d) was determined from the number of molecules of electrochemically deposited quantum dots assuming that they uniform film. The number of deposited molecules was calculated from the charge that passed during film electrodeposition (minus the amount of charge that passed through the film during de-doping). Area of the film (A) was obtained as a fitting parameter at the faradaic current modeling (see next section).

Table S1. Experimental and fitting parameters for capacitive current of HBC and CQD.

\begin{tabular}{|c|c|c|}
\hline parameter & HBC & CQD \\
\hline \multicolumn{3}{|c|}{ experimental } \\
\hline $\mathrm{d}(\mathrm{cm})$ & $4.75 \cdot 10^{-4}$ & $3.6 \cdot 10^{-4}$ \\
\hline \multicolumn{3}{|c|}{ fitting } \\
\hline $\mathrm{A}\left(\mathrm{cm}^{2}\right)$ & 0.06 & 0.06 \\
\hline
\end{tabular}




\begin{tabular}{|c|c|c|}
\hline $\mathrm{R}_{\mathrm{s}}(\Omega)$ & 3000 & 3000 \\
\hline $\mathrm{A}_{0}\left(\mathrm{~V}^{-1} \mathrm{~cm}^{-3}\right)$ & $3.29 \cdot 10^{18}$ & $1.3 \cdot 10^{19}$ \\
\hline $\mathrm{A}_{1}\left(\mathrm{~V}^{-1} \mathrm{~cm}^{-3}\right)$ & $1.5 \cdot 10^{21}$ & $0.5 \cdot 10^{21}$ \\
\hline $\mathrm{A}_{2}\left(\mathrm{~V}^{-1} \mathrm{~cm}^{-3}\right)$ & $4.6 \cdot 10^{21}$ & $0.4 \cdot 10^{21}$ \\
\hline $\mathrm{A}_{3}\left(\mathrm{~V}^{-1} \mathrm{~cm}^{-3}\right)$ & $1.3 \cdot 10^{21}$ & $1 \cdot 10^{21}$ \\
\hline $\mathrm{A}_{4}\left(\mathrm{~V}^{-1} \mathrm{~cm}^{-3}\right)$ & $1 \cdot 10^{21}$ & $0.6 \cdot 10^{21}$ \\
\hline $\mathrm{E}_{01}(\mathrm{~V})$ & 0.7 & 0.1 \\
\hline $\mathrm{E}_{02}(\mathrm{~V})$ & 0.85 & 0.5 \\
\hline $\mathrm{E}_{03}(\mathrm{~V})$ & 1.1 & 1.15 \\
\hline $\mathrm{E}_{04}(\mathrm{~V})$ & 1.5 & 1.25 \\
\hline$\sigma_{1}(\mathrm{~V})$ & 0.008 & 0.14 \\
\hline$\sigma_{2}(\mathrm{~V})$ & 0.002 & 0.07 \\
\hline$\sigma_{3}(\mathrm{~V})$ & 0.001 & 0.08 \\
\hline$\sigma_{4}(\mathrm{~V})$ & 1 & 0.03 \\
\hline
\end{tabular}

\section{Faradaic Current:}

The total current in the presence of $\mathrm{Fc}$ is modeled as a sum of the capacitive current $\mathrm{I}_{\mathrm{c}}$ (see previous section for details) and the faradaic current, $\mathrm{I}_{\mathrm{F}}$, due to the interfacial charge transfer:

$I=I_{C}+I_{F}$

The faradaic current is directly proportional to the flux of Fc molecules to the electrode surface, which is described using Fick's second law of diffusion:

$\frac{\partial c_{F c}}{\partial t}=D \frac{\partial^{2} c_{F c}}{\partial x^{2}}$

where $\mathrm{c}_{\mathrm{Fc}}$ is concentration of ferrocene, $\mathrm{t}$ is time, $\mathrm{D}$ is the diffusion coefficient of $\mathrm{Fc}$, and $\mathrm{x}$ is the distance from the electrode. Similarly, concentration of $\mathrm{Fc}^{+}, \mathrm{c}_{\mathrm{Fc}}$, could be obtained (assuming D is the same for $\mathrm{Fc}$ and $\mathrm{Fc}^{+}$): 
$\frac{\partial c_{F c+}}{\partial t}=D \frac{\partial^{2} c_{F c+}}{\partial x^{2}}$

Partial differential equations 11 and 12 were solved using the following initial and boundary conditions:

$t=0, x \geq 0$ and $t \geq 0, x=\infty: c_{F c}=c^{0}, c_{F c+}=0$

where $c^{0}$ is the initial concentration of ferrocene. The second boundary condition represents the conservation of fluxes of $\mathrm{Fc}$ and $\mathrm{Fc}^{+}$and, if we assume that diffusion coefficients for $\mathrm{Fc}$ and $\mathrm{Fc}^{+}$ are the same, it could be written as:

$t \geq 0, x=0: \frac{\partial c_{F c}}{\partial x}+\frac{\partial c_{F c+}}{\partial x}=0$

and

$D\left(\frac{\partial c_{F c+}}{\partial x}\right)_{x=0}=\left[k_{f} \cdot\left(c_{F c}\right)_{x=0}-k_{b} \cdot\left(c_{F c+}\right)_{x=0}\right]$

Differential equation 15 was solved using the numerical method that was previously described. ${ }^{9-}$ ${ }^{10}$ Matlab was used for fitting. The faradaic current, which is related to rate constants for Fc oxidation $\left(\mathrm{k}_{\mathrm{f}}\right)$ and $\mathrm{Fc}^{+}$reduction $\left(\mathrm{k}_{\mathrm{b}}\right)$, could be written as:

$I_{F}=F \cdot A \cdot\left[k_{f} \cdot\left(c_{F c}\right)_{x=0}-k_{b} \cdot\left(c_{F c+}\right)_{x=0}\right]$

Here, $\mathrm{F}$ is Faraday's constant and A is electrode surface area.

Rate constants $\mathrm{k}_{\mathrm{f}}$ and $\mathrm{k}_{\mathrm{b}}$ were obtained using the Marcus-Gerischer model ${ }^{11-12}$ from density of states (DOS) values for HBC/CQD electrodes and probabilities of finding the empty/occupied state of $\mathrm{Fc}$ at a given potential $\left(\mathrm{W}_{\mathrm{ox}}\right.$ and $\mathrm{W}_{\text {red }}$ ). Those equations are derived assuming zero temperature limit for the Fermi-Dirac distribution ${ }^{11}$ : 
$k_{f}=k_{t} \cdot W_{\text {red }} \cdot$ DOS

$k_{b}=k_{t} \cdot W_{o x} \cdot D O S$

Here, $\mathrm{k}_{\mathrm{t}}$ is the tunneling probability constant. The probabilities $\mathrm{W}_{\text {ox }}$ and $\mathrm{W}_{\text {red }}$ were expressed using the Gerischer equation, which places state density maxima at $\mathrm{E}_{\mathrm{o}} \pm \lambda$ values (where $\mathrm{E}_{\mathrm{o}}$ is the $\mathrm{Fc} / \mathrm{Fc}^{+}$ standard reduction potential and $\lambda$ is the reorganization energy associated with the redox process:

$W_{o x}=\frac{e}{\sqrt{4 k T \lambda}} e^{\left(-\frac{\left(e V-e E_{0}+\lambda\right)^{2}}{4 k T \lambda}\right)}$

$W_{\text {red }}=\frac{e}{\sqrt{4 k T \lambda}} e^{\left(-\frac{\left(e V-e E_{0}-\lambda\right)^{2}}{4 k T \lambda}\right)}$

where $\mathrm{k}$ is Boltzmann constant, $\mathrm{T}$ is absolute temperature, $\mathrm{e}$ is elemental charge, and $\mathrm{V}$ is the voltage. Differential equations 11 and 12 were solved and total current, I, was calculated. Then data were fit to the experimental values using Matlab. Diffusion coefficient for Fc in DCM (with $0.1 \mathrm{M} \mathrm{TBAPF}_{6}$ as electrolyte) was previously reported as $1.67 \cdot 10^{-5} \mathrm{~cm}^{2} / \mathrm{s}$ and we used that value in our model. ${ }^{13} \mathrm{E}^{0}$ was obtained experimentally from $\mathrm{CVs}$ of $\mathrm{Fc}$ on Pt working electrode and it was found to be $0.23 \mathrm{~V}$. Reorganization energy, $\lambda$, and tunneling probability constant, $\mathrm{k}_{\mathrm{t}}$, and surface area (A) were parameters varied to find the best fit. Table S2 lists experimental and fitting parameters used in this model. 
Table S2. Experimental and fitting parameters for faradaic current.

\begin{tabular}{|c|c|c|}
\hline parameter & HBC & CQD \\
\hline \multicolumn{3}{|c|}{ experimental } \\
\hline $\mathrm{c}_{0}\left(\mathrm{~mol} / \mathrm{cm}^{3}\right)$ & $3 \cdot 10^{-6}$ & $3 \cdot 10^{-6}$ \\
\hline $\mathrm{D}\left(\mathrm{cm}^{2} / \mathrm{s}^{13}\right.$ & $1.67 \cdot 10^{-5}$ & $1.67 \cdot 10^{-5}$ \\
\hline $\mathrm{E}_{0}(\mathrm{~V})$ & 0.231 & 0.231 \\
\hline scan rate $(\mathrm{mV} / \mathrm{s})$ & 50 & 50 \\
\hline \multicolumn{3}{|c|}{} \\
\hline$\lambda(\mathrm{V})$ & fitting & 0.42 \\
\hline $\mathrm{A}\left(\mathrm{cm}^{2}\right)$ & 0.42 & 0.06 \\
\hline $\mathrm{k}_{\mathrm{t}}\left(\mathrm{cm}^{4} / \mathrm{s}\right)$ & 0.06 & $3 \cdot 10^{-23}$ \\
\hline
\end{tabular}
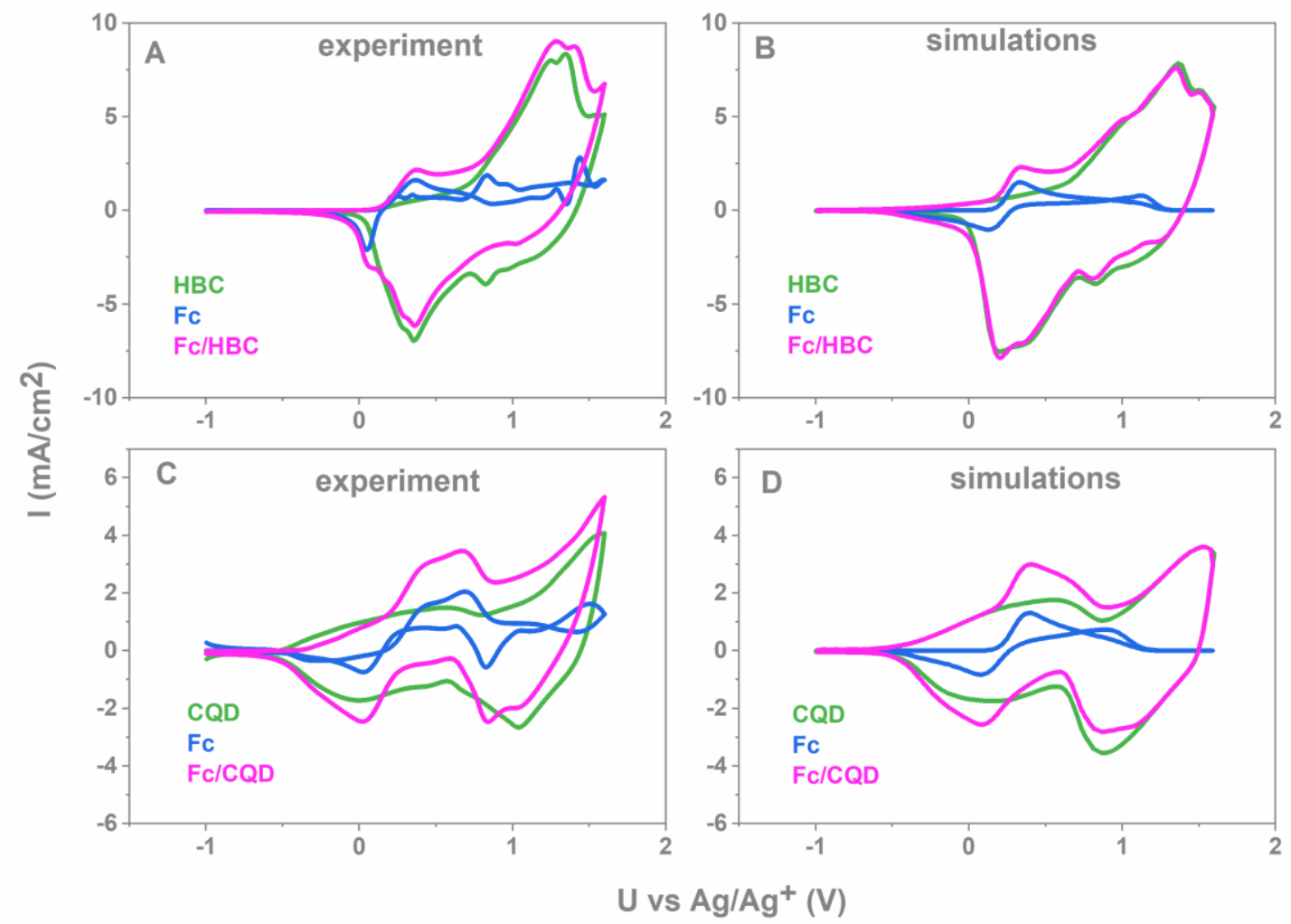

Figure S12. Experimental CVs of A) $\mathrm{HBC}$ and C) $\mathrm{CQD}$ film in $0.1 \mathrm{M} \mathrm{TBAPF}_{6}$ in $\mathrm{CH}_{2} \mathrm{Cl}_{2}$ (green lines). Pink lines represent voltammograms collected in the presence of $3 \mathrm{mM} \mathrm{Fc}$. Blue line is 
showing faradaic current which was obtained as a difference between total and capacitive currents. Scan rate: $50 \mathrm{mV} / \mathrm{s}$. Simulated CVs of B) HBC and D) CQD films. Green scans represent capacitive currents $\left(\mathrm{I}_{\mathrm{C}}\right)$, blue is faradaic $\left(\mathrm{I}_{\mathrm{F}}\right)$ and total current is pink $(\mathrm{I})$.
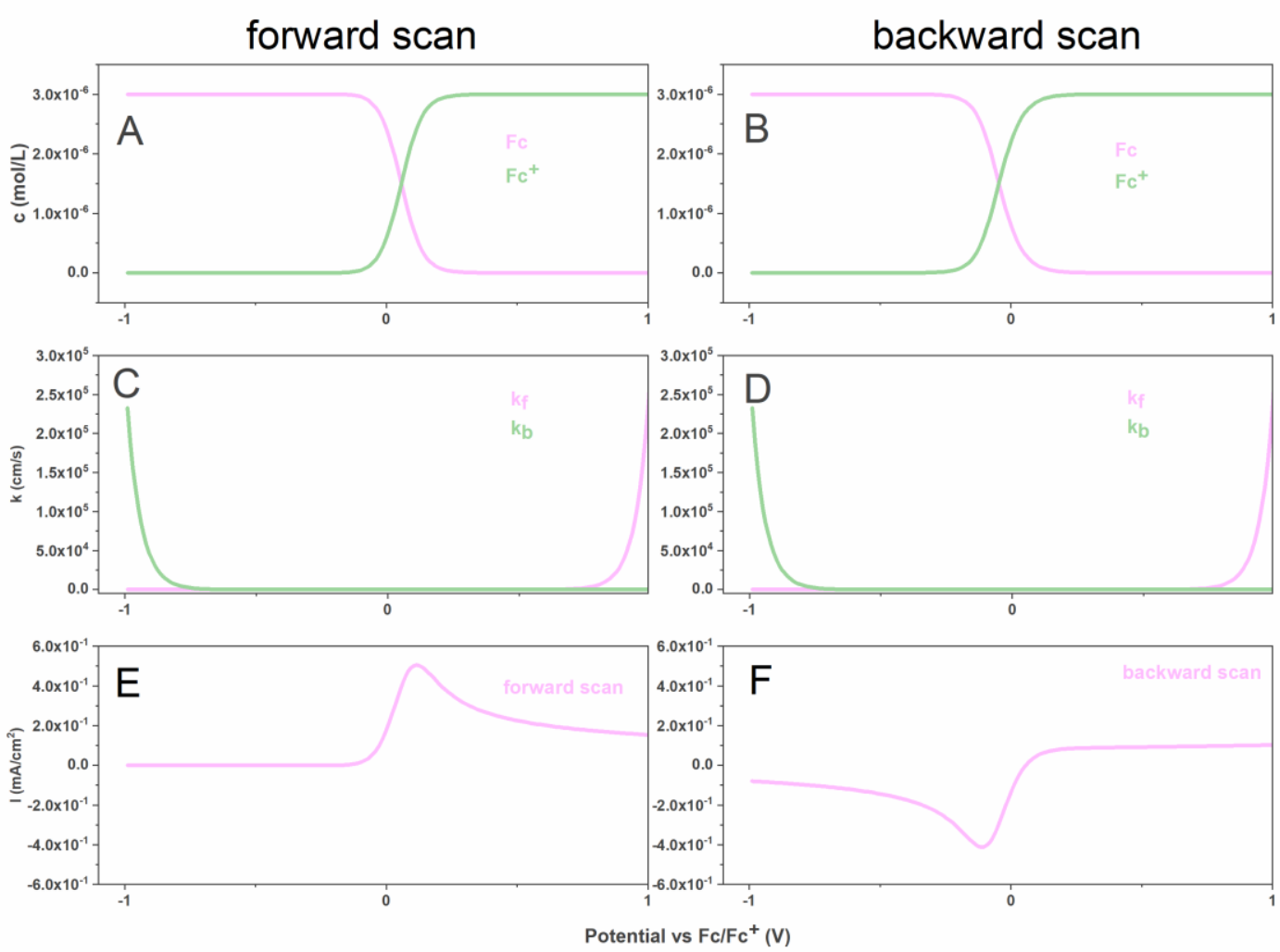

Figure S13. Simulated concertation profiles using Butler-Volmer model for reduced (Fc, pink line) and oxidized $\left(\mathrm{Fc}^{+}\right.$, green line) species at the electrode surface during the A) forward and B) backward scan for the electrode exhibiting Butler-Volmer kinetics. C and D show rate constants for forward (oxidation, pink line) and backward (reduction, green line) electron transfer reactions. $\mathrm{E}$ and $\mathrm{F}$ present simulated cyclic voltammograms for $\mathrm{E})$ forward $(-1 \rightarrow 1.6 \mathrm{~V})$ and $\mathrm{F}$ ) backward $(1.6 \rightarrow-1 \mathrm{~V})$ scan. $\mathrm{k}_{0}=1 \cdot 10^{-3} \mathrm{~cm} / \mathrm{s}, \mathrm{E}_{0}=0 \mathrm{~V}, \mathrm{D}=1.67 \cdot 10^{-5} \mathrm{~cm}^{2} / \mathrm{s}, \mathrm{A}=0.06 \mathrm{~cm}^{2}$. 

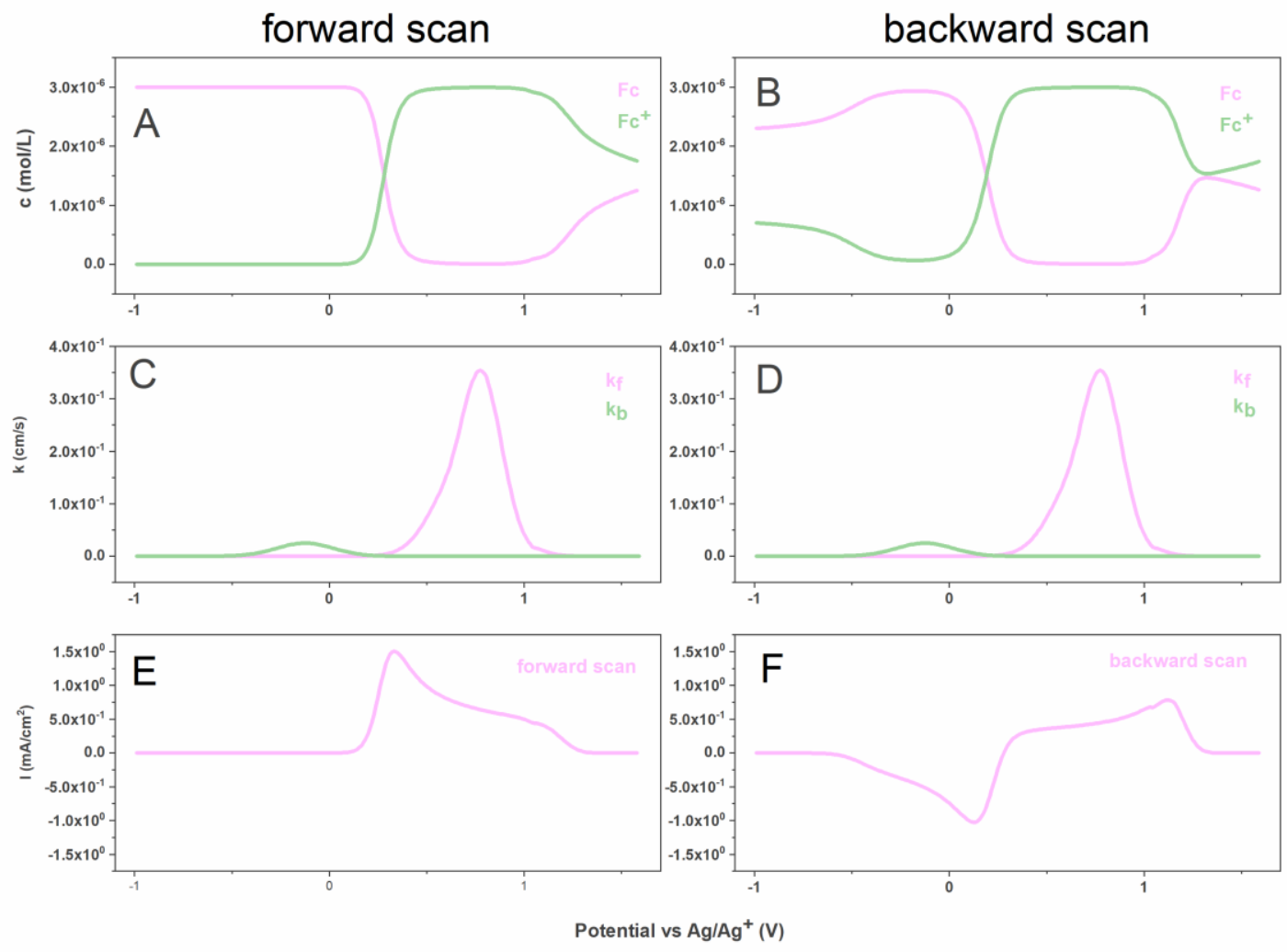

Figure S14. Simulated concertation profiles using Marcus-Gerischer model for reduced (Fc, pink line) and oxidized $\left(\mathrm{Fc}^{+}\right.$, green line) species at the $\mathrm{HBC}$ electrode surface during the A) forward and B) backward scan. C and D show rate constants for forward (oxidation, pink line) and backward (reduction, green line) electron transfer reactions. E and F present simulated cyclic voltammograms for E) forward $(-1 \rightarrow 1.6 \mathrm{~V})$ and F) backward $(1.6 \rightarrow-1 \mathrm{~V})$ scan. DOS was modeled as previously described and parameters are listed in Tables S1 and S2. 

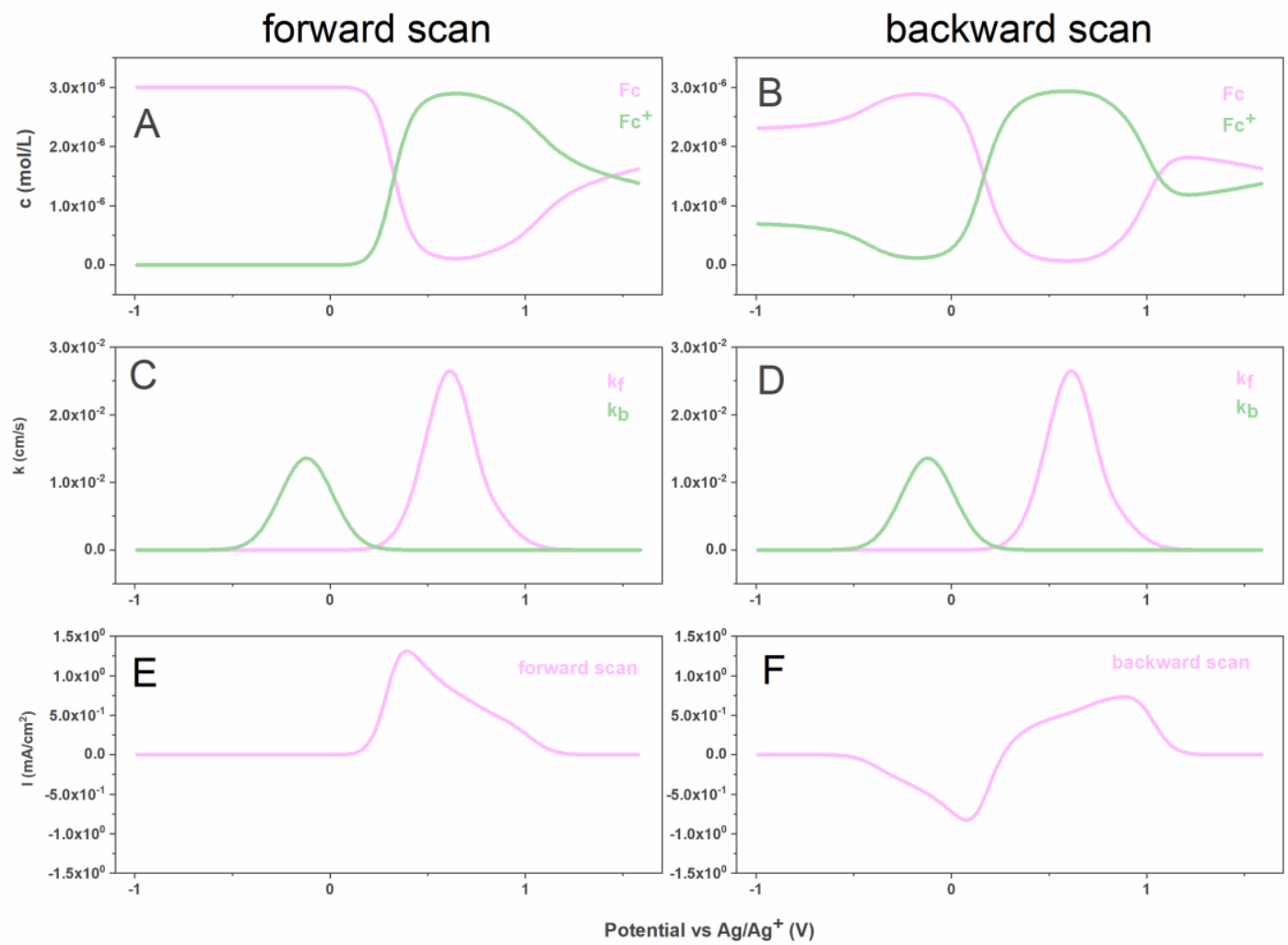

Figure S15. Simulated concertation profiles using Marcus-Gerischer model for reduced (Fc, pink line) and oxidized $\left(\mathrm{Fc}^{+}\right.$, green line) species at the CQD electrode surface during the A) forward and B) backward scan. C and D are showing rate constants for forward (oxidation, pink line) and backward (reduction, green line) electron transfer reactions. E and F are presenting simulated cyclic voltammograms for E) forward $(-1 \rightarrow 1.6 \mathrm{~V})$ and $\mathrm{F}$ ) backward $(1.6 \rightarrow-1 \mathrm{~V})$ scan. DOS was modeled as previously described and parameters are listed in Tables S1 and S2.

\section{S6. Impedance measurements}

Electrochemical impedance spectroscopy (EIS) measurements were performed in $1 \mathrm{M} \mathrm{TBAPF}_{6}$ solution in DCM using 0.1 $\mathrm{M} \mathrm{Ag/AgNO} 3$ electrode as reference, $\mathrm{Pt}$ wire as counter, and either Pt or HBC deposited onto Pt as the working electrode. Potentiostatic EIS experiments were collected using AC voltage of $10 \mathrm{mV}$ and frequency range of $10 \mathrm{mHz}$ to $30 \mathrm{kHz}$. The experiments were conducted at open circuit potential. CVs of HBC were collected before and after each experiment to ensure that the film was unchanged. The experiments without HBC (only Pt as working electrode) were also performed. 
To compare parameters obtained from EIS measurements with those gained from simulations, CV and EIS experimental data were simulated using the circuits presented in Figure S17. The circuit for $\mathrm{CV}$ simulations is consistent with equations 1-3 in the main manuscript. Fitting parameters form CV measurements are listed in Table S3. The values are slightly different from the fits obtained in the main manuscript, due to the irreproducibility in the HBC electrodeposition. Namely, cyclic voltammograms of HBC films are slightly different (Figure 3 and Figure S16), even though great care was made to ensure identical experimental conditions.

The EIS data were modeled using the circuit (Figure S17B) that represents a lumped transmission line model for a porous electrode in background electrolyte. ${ }^{14}$ Constant phase elements (CPE), Q, were used instead of ideal capacitors due to the roughness of the HBC electrode. Capacitance was calculated from the CPEs using equations shown previously. ${ }^{15}$ The parameters obtained from EIS fits are listed in Table S4.

EIS data for Pt electrode was modeled using $\mathrm{R}_{\mathrm{s}} \mathrm{-} \mathrm{C} \| \mathrm{W}$ circuit and parameters are listed in Table S5, where $\mathrm{W}$ stands for the Warburg element and models semi-infinite diffusion to the planar Pt working electrode.

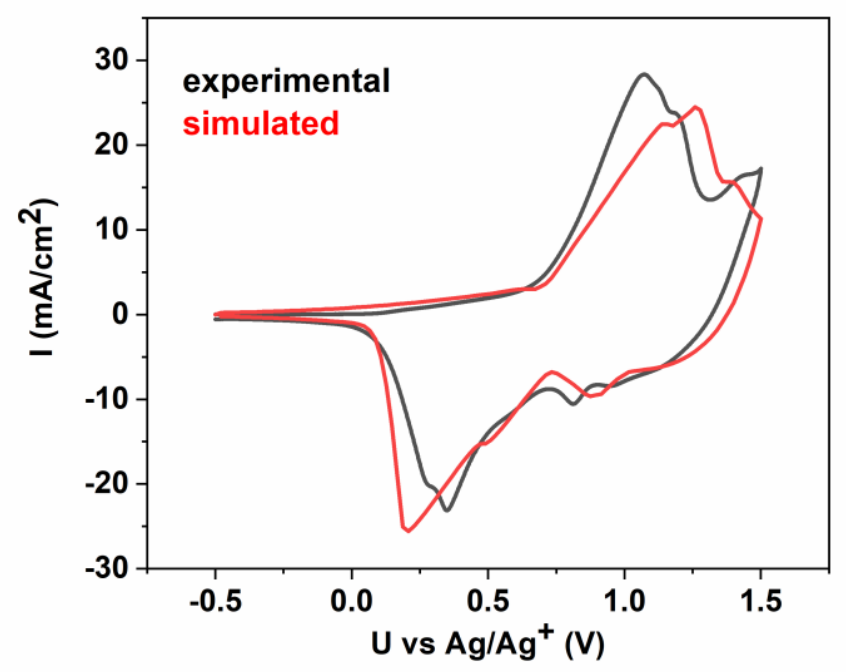

Figure S16. Experimental (black) and simulated (red) CVs of HBC film used for EIS. Scan rate: $100 \mathrm{mV} / \mathrm{s}$. 
Table S3. Experimental and fitting parameters for capacitive current of $\mathrm{HBC}$ obtained by fitting the CV data using equations 1-3.

\begin{tabular}{|c|c|}
\hline parameter & value \\
\hline \multicolumn{2}{|c|}{ experimental } \\
\hline $\mathrm{d}(\mathrm{cm})$ & $4.75 \cdot 10^{-4}$ \\
\hline \multicolumn{2}{|c|}{ simulated } \\
\hline $\mathrm{A}\left(\mathrm{cm}^{2}\right)$ & 0.06 \\
\hline $\mathrm{R}_{\mathrm{s}}(\Omega)$ & 900 \\
\hline $\mathrm{A}_{0}\left(\mathrm{~V}^{-1} \mathrm{~cm}^{-3}\right)$ & $3.29 \cdot 10^{18}$ \\
\hline $\mathrm{A}_{1}\left(\mathrm{~V}^{-1} \mathrm{~cm}^{-3}\right)$ & $1.3 \cdot 10^{22}$ \\
\hline $\mathrm{A}_{2}\left(\mathrm{~V}^{-1} \mathrm{~cm}^{-3}\right)$ & $5.5 \cdot 10^{21}$ \\
\hline $\mathrm{A}_{3}\left(\mathrm{~V}^{-1} \mathrm{~cm}^{-3}\right)$ & $1.3 \cdot 10^{21}$ \\
\hline $\mathrm{A}_{4}\left(\mathrm{~V}^{-1} \mathrm{~cm}^{-3}\right)$ & $1 \cdot 10^{21}$ \\
\hline $\mathrm{E}_{01}(\mathrm{~V})$ & 0.7 \\
\hline $\mathrm{E}_{02}(\mathrm{~V})$ & 0.8 \\
\hline $\mathrm{E}_{03}(\mathrm{~V})$ & 1.1 \\
\hline $\mathrm{E}_{04}(\mathrm{~V})$ & 1.5 \\
\hline$\sigma_{1}(\mathrm{~V})$ & 0.001 \\
\hline$\sigma_{2}(\mathrm{~V})$ & 0.001 \\
\hline$\sigma_{3}(\mathrm{~V})$ & 0.001 \\
\hline$\sigma_{4}(\mathrm{~V})$ & 1 \\
\hline capacity $(\mathrm{F})$ at $\mathrm{OCP}$ & $2.34 \cdot 10^{-4}$ \\
\hline
\end{tabular}

A

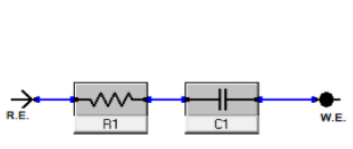

B

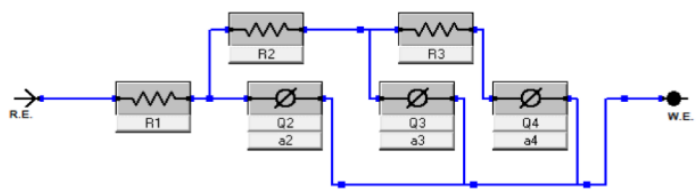

C

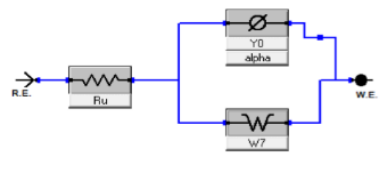

Figure S17. A) Circuit used for modeling of CVs. B) Circuit used for EIS modeling of HBC film. C) Circuit used for modeling of EIS at Pt; $R_{i}$ are resistors with resistance of $R_{i}, C_{1}$ is the capacitor 
with capacitance $C_{i}$. $Q_{i}$ are constant phase elements used to model capacitance of rough HBC electrode surfaces. W represents Warburg element.
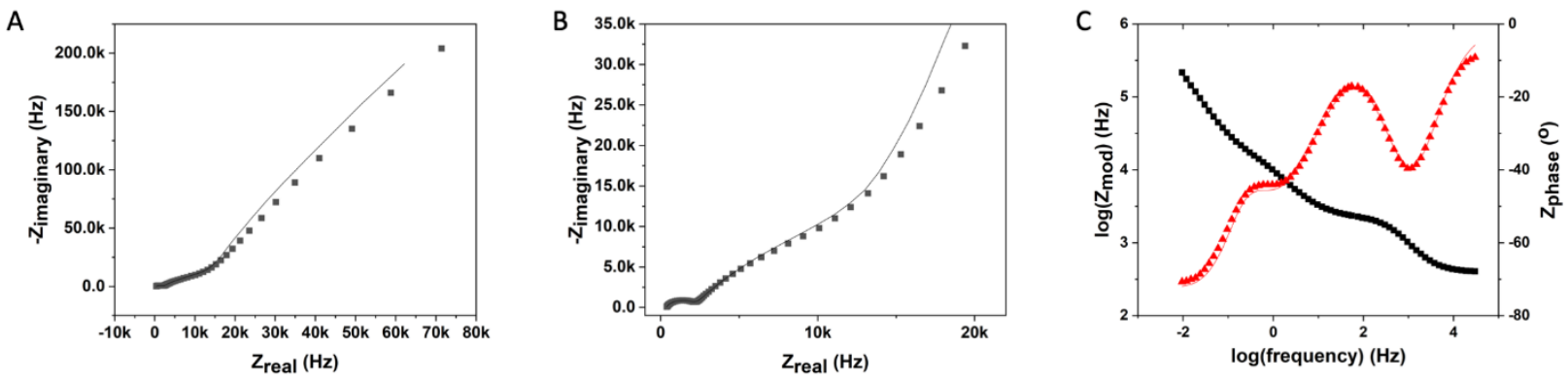

Figure S18. A) Nyquist plot of EIS data of HBC at the OCP in background electrolyte. B) Magnified higher frequency range of Nyquist plot of EIS data of HBC at the OCP in background electrolyte. C) Bode plot of EIS data of HBC at the OCP in background electrolyte (black line corresponds to the left y-axis while red one is for the y-axis on the right-hand side). Dots are experimental data and solid lines are model fits.

Table S4. Parameters evaluated from EIS measurements of HBC film.

\begin{tabular}{|l|l|}
\hline parameter & value \\
\hline $\mathrm{R}_{1}(\Omega)$ & 392.8 \\
\hline $\mathrm{R}_{2}(\Omega)$ & 1890 \\
\hline $\mathrm{R}_{3}(\Omega)$ & 39100 \\
\hline $\mathrm{C}_{2}(\mathrm{~F})$ & $1.61 \cdot 10^{-7}$ \\
\hline $\mathrm{C}_{3}(\mathrm{~F})$ & $5.06 \cdot 10^{-6}$ \\
\hline $\mathrm{C}_{4}(\mathrm{~F})$ & $2.63 \cdot 10^{-5}$ \\
\hline $\mathrm{F}_{2}(\mathrm{characteristic}$ frequency) $(\mathrm{Hz})$ & 3280 \\
\hline $\mathrm{F}_{3}(\mathrm{~Hz})$ & 505 \\
\hline
\end{tabular}

The equivalent circuit required to model EIS data was more complex than that used to model CV data. This is because EIS deconvolutes the ionic resistances and capacitances at different locations within the porous $\mathrm{HBC}$ electrodes by examining them across a range of frequencies. Capacitance at the electrode surface is probed at high frequencies, while ionic transport into the pores is probed at lower frequencies. 
In Figure $\mathrm{S} 17$ and Table $\mathrm{S} 2, \mathrm{R}_{1}$ is the ohmic resistance between working and reference electrodes; $\mathrm{C}_{2}$ is the capacitance at the surface of the electrode; $\mathrm{R}_{2}$ is the ionic transport resistance from the surface into the pore; and $\mathrm{C}_{3}$ and $\mathrm{R}_{3}$ represent the ionic transport resistance and capacitance deeper into the pore.

The total capacitance of the HBC electrode calculated from CV was $234 \mu \mathrm{F}$. This value was within an order of magnitude of the capacitance value determined from EIS $(32 \mu \mathrm{F})$. The resistance, $\mathrm{R}_{2}$, likely representing the resistance due to ion intercalation into the $\mathrm{HBC}$ films, was $1.8 \mathrm{k} \Omega$. This value was similar to the overall ionic resistance determined from the CV model $(900 \Omega)$. The resistance value, $R_{3}$, representing the ionic resistance deep into the pore, was more than an order of magnitude greater than the resistance obtained through $\mathrm{CV}$ experiments and the associated model. This data was only accessible by EIS measurements at low frequencies and was not measurable during $\mathrm{CV}$ scans.

A

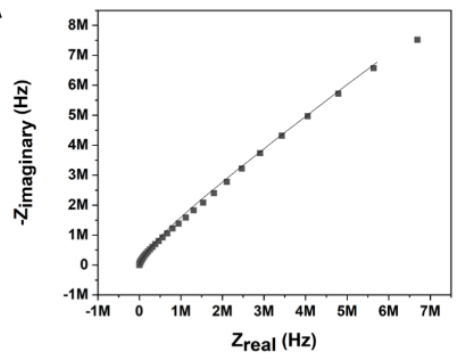

B

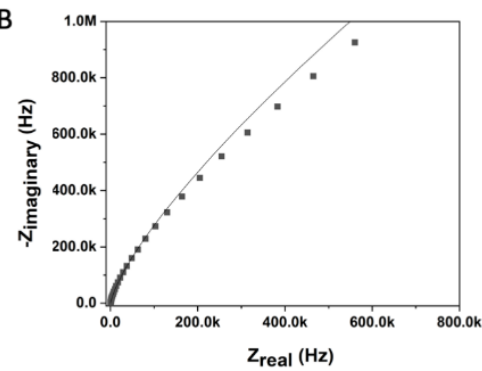

C

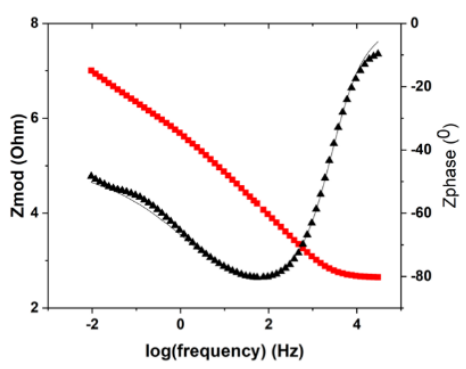

Figure S19. A) Nyquist plot of Pt EIS at OCP in background electrolyte. B) Magnified higher frequency range of Nyquist plot of Pt EIS at OCP in background electrolyte. C) Bode plot of Pt EIS at OCP in background electrolyte (black line corresponds to the left y-axis while red one is for the y-axis on the right-hand side). Dots are experimental data while solid lines are fit.

Table S5 illustrates the equivalent circuit model values obtained from the EIS measurements performed on a Pt electrode. The capacitance of Pt electrode obtained from CV measurements was $3 \mu \mathrm{F}$. The capacitance of the Pt electrode determined from EIS experiments was an order of magnitude less. Therefore, it has been shown that capacitance values of Pt and HBC electrode, obtained from CV experiments and the associated model, are up to an order of magnitude greater than the values obtained from EIS experiments. Similar difference between EIS and CV values 
have been reported previously and result from the polarization of non-ideal capacitors further away from OCP in CV measurements. ${ }^{16}$

Table S5. Parameters evaluated from EIS measurements of Pt electrode.

\begin{tabular}{|l|l|}
\hline parameter & value \\
\hline $\mathrm{R}_{\mathrm{s}}(\Omega)$ & 448.2 \\
\hline $\mathrm{C}(\mathrm{F})$ & $1.38 \cdot 10^{-7}$ \\
\hline $\mathrm{W}\left(\mathrm{S} \mathrm{s}^{-1 / 2}\right)$ & $4.16 \cdot 10^{-7}$ \\
\hline
\end{tabular}

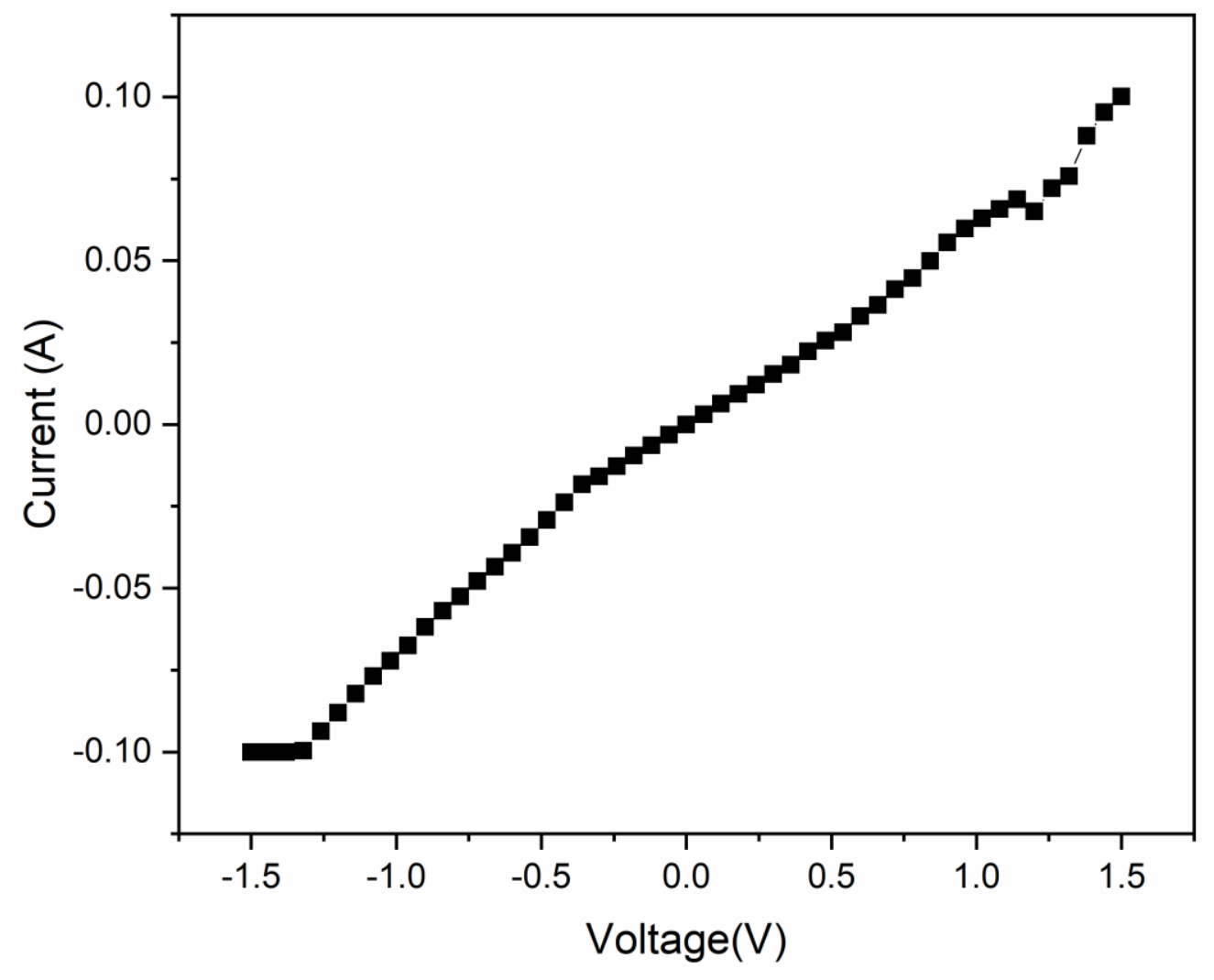

Figure S20. IV curve for HBC film deposited onto Pt electrode collected using 2-point-probe measurements. 
Two-point-probe measurements were performed on the HBC electrodes. The experiments were run on a Keithley 2126 instrument. Resistance obtained from those measurements was $15 \Omega$, suggesting good electronic conductivity of HBC. This result is consistent with CV experiments, suggesting that ionic resistance is dominant. 


\section{S7. References}

1. Liu, R.; Wu, D.; Feng, X.; Müllen, K., Bottom-Up Fabrication of Photoluminescent Graphene Quantum Dots with Uniform Morphology. J. Am. Chem. Soc. 2011, 133 (39), 1522115223.

2. Ito, S.; Wehmeier, M.; Brand, J. D.; Kübel, C.; Epsch, R.; Rabe, J. P.; Müllen, K., Synthesis and Self-Assembly of Functionalized Hexa-peri-hexabenzocoronenes. Eur. J. Chem. 2000, 6 (23), 4327-4342.

3. Schlütter, F.; Nishiuchi, T.; Enkelmann, V.; Müllen, K., $\pi$-Congested Poly(para phenylene) from 2, 2', 6, 6'-tetraphenyl-1, 1'-biphenyl Units: Synthesis and Structural Characterization. Pol. Chem. 2013, 4 (10), 2963-2967.

4. Qin, L.; Zhang, Y.; Wu, X.; Nian, L.; Xie, Z.; Liu, L.; Ma, Y., In Situ Electrochemical Synthesis and Deposition of Discotic Hexa-peri-hexabenzocoronene Molecules on Electrodes: SelfAssembled Structure, Redox Properties, and Application for Supercapacitor. Small 2015, 11 (25), 3028-3034.

5. Malard, L.; Pimenta, M.; Dresselhaus, G.; Dresselhaus, M., Raman Spectroscopy in Graphene. Phys. Rep. 2009, 473 (5-6), 51-87.

6. Fabregat-Santiago, F.; Mora-Seró, I.; Garcia-Belmonte, G.; Bisquert, J., Cyclic Voltammetry Studies of Nanoporous Semiconductors. Capacitive and Reactive Properties of Nanocrystalline TiO2 Electrodes in Aqueous Electrolyte. J. Phys. Chem. B 2003, 107 (3), 758-768.

7. Bisquert, J.; Fabregat-Santiago, F.; Mora-Seró, I.; Garcia-Belmonte, G.; Barea, E. M.; Palomares, E., A review of Recent Results on Electrochemical Determination of the Density of Electronic States of Nanostructured Metal-Oxide Semiconductors and Organic Hole Conductors. Inorganica Chim. Acta 2008, 361 (3), 684-698.

8. Rudolph, M.; Ratcliff, E. L., Normal and Inverted Regimes of Charge Transfer Controlled by Density of States at Polymer Electrodes. Nat. Commun. 2017, 8 (1), 1048.

9. Samin, A.; Lahti, E.; Zhang, J., Analytical Solutions of the Planar Cyclic Voltammetry Process for Two Soluble Species ith Equal Diffusivities and Fast Electron Transfer Using the Method of Eigenfunction Expansions. AIP Adv. 2015, 5 (8), 087141.

10. Brown, J. H., Development and Use of a Cyclic Voltammetry Simulator to Introduce Undergraduate Students to Electrochemical Simulations. J. Chem. Educ. 2015, 92 (9), 1490-1496.

11. Memming, R., Semiconductor Electrochemistry. John Wiley \& Sons: 2015.

12. Gerischer, H., Charge Transfer Processes at Semiconductor-Electrolyte Interfaces in Connection with Problems of Catalysis. Surf. Sci. 1969, 18 (1), 97-122.

13. Tsierkezos, N. G., Cyclic Voltammetric Studies of Ferrocene in Nonaqueous Solvents in the Temperature Range from 248.15 to 298.15 K. J. Sol. Chem. 2007, 36 (3), 289-302.

14. https://www.gamry.com/application-notes/EIS/use-of-transmission-lines-for-eis/ 15.https://www.gamry.com/application-notes/EIS/basics-of-electrochemical-impedancespectroscopy/ 
16. Randviir, E.; Metters, J.; Stainton, J.; Banks, C., Electrochemical Impedance Spectroscopy versus Cyclic Voltammetry for the Electroanalytical Sensing of Capsaicin Utilising Screen Printed Carbon Nanotube Electrodes. Analyst 2013, 138, 2970 